\title{
The Role of Buoy and Argo Observations in Two SST Analyses in the Global and Tropical Pacific Oceans
}

\author{
BOYIN HUANG \\ NOAA National Centers for Environmental Information, Asheville, North Carolina \\ CHUNYING LiU \\ ERT, Inc., Laurel, Maryland \\ GUOYU REN
}

National Climate Center, China Meteorological Administration, Beijing, and Department of Atmospheric Science, School of Environmental Studies, China University of Geosciences, Wuhan, China

HUAI-MiN ZHANG

NOAA National Centers for Environmental Information, Asheville, North Carolina

\author{
LEI ZHANG
}

National Meteorological Information Center, China Meteorological Administration, Beijing, China

(Manuscript received 6 June 2018, in final form 4 October 2018)

\begin{abstract}
The relative roles of buoy and Argo observations in two sea surface temperature (SST) analyses are studied in the global ocean and tropical Pacific Ocean over 2000-16 using monthly Extended Reconstructed SST version 5 (ERSSTv5) and Daily Optimum Interpolation SST version 2 (DOISST). Experiments show an overall higher impact by buoys than Argo floats over the global oceans and an increasing impact by Argo floats. The impact by Argo floats is generally larger in the Southern Hemisphere than in the Northern Hemisphere. The impact on trends and anomalies of globally averaged SST by either one is small when the other is used. The warming trend over 2000-16 remains significant by including either buoys or Argo floats or both. In the tropical Pacific, the impact by buoys was large over 2000-05 when the number of Argo floats was low, and became smaller over 2010-16 when the number and area coverage of Argo floats increased. The magnitude of El Niño and La Niña events decreases when the observations from buoys, Argo floats, or both are excluded. The impact by the Tropical Atmosphere Ocean (TAO) and Triangle Trans-Ocean Buoy Network (TRITON) is small in normal years and during El Niño events. The impact by TAO/TRITON buoys on La Niña events is small when Argo floats are included in the analysis systems, and large when Argo floats are not included. The reason for the different impact on El Niño and La Niña events is that the drifting buoys are more dispersed from the equatorial Pacific region by stronger trade winds during La Niña events.
\end{abstract}

\section{Introduction}

Ocean analyses, reanalyses, and predictions rely on the observations from a variety of platforms, including ships, drifting buoys, moored buoys, Argo floats (Argo 2018; Roemmich et al. 2001), and satellites. However, these observing systems changed a lot over time. For example, Argo observations have been increasing rapidly

Corresponding author: Boyin Huang, boyin.huang@noaa.gov since 2000, whereas the observations from the Tropical Atmosphere-Ocean (TAO) and Triangle Trans-Ocean Buoy Network (TRITON) in the tropical Pacific (McPhaden et al. 1998) decreased by $40 \%$ after 2011 due to vandalism and lack of maintenance resources (Teng et al. 2009; Tollefson 2014; Xue et al. 2017) but were partially recovered by restored maintenance after 2014 (Figs. 1d and 1e). Therefore, it is important to understand the impacts of the changes in these observing systems on ocean analyses and forecasts, which are commonly 
(a) Obs num in $\log 10$ scale, Glb

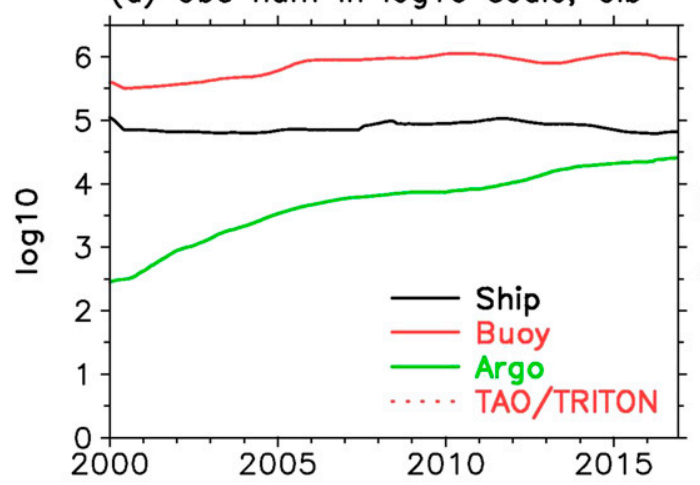

(b) Individual obs coverage, Glb

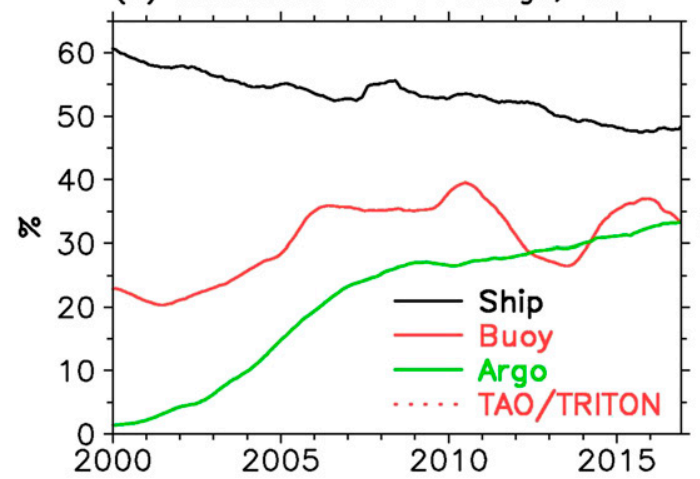

(c) Accumulated obs coverage, Glb

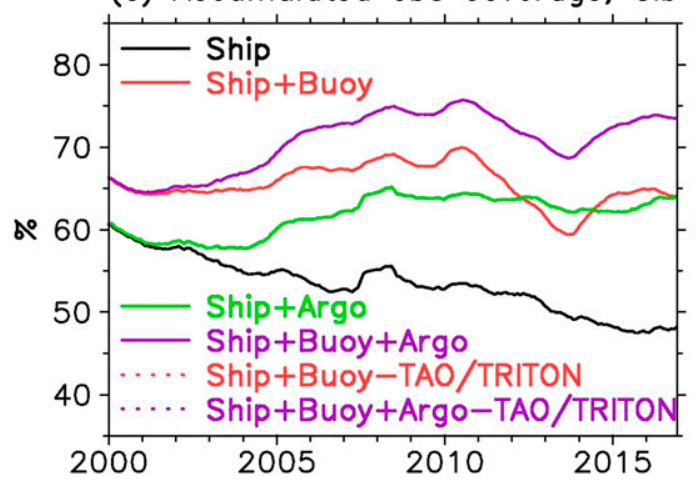

(d) Obs num in $\log 10$ scale, Pac

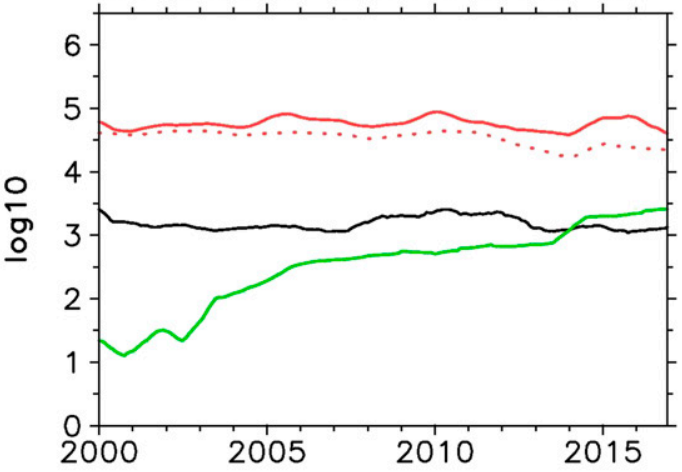

(e) Individual obs coverage, Pac

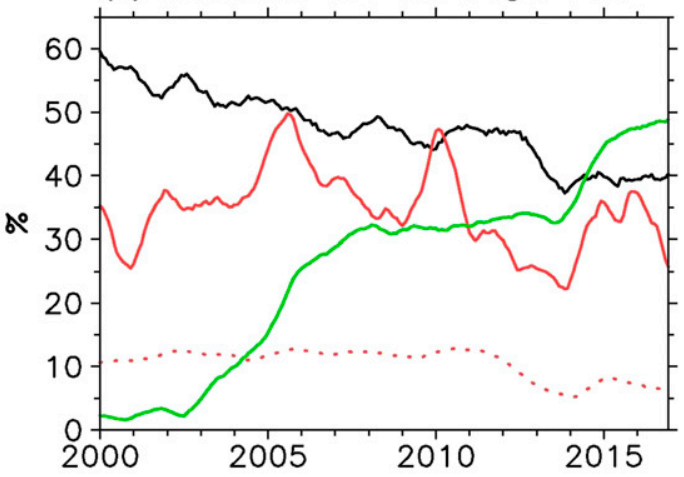

(f) Accumulated obs coverage, Pac

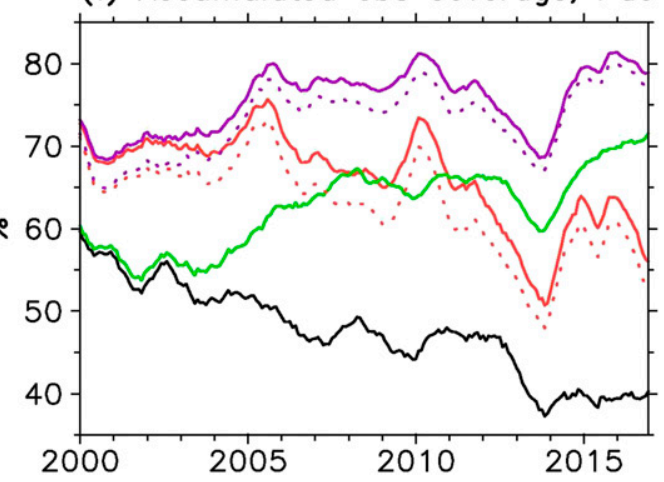

FIG. 1. (a) Numbers of SST observations ( $\log _{10}$ scale) from ships (solid black), buoys (solid red), and Argo floats (solid green). (b) Area coverages of SST observations from ships (solid black), buoys (solid red), and Argo floats (solid green). (c) Area coverages of SST observations from ships (solid black); ships and buoys (solid red); ships, and Argo floats (solid green); and ships, buoys, and Argo floats (solid purple) in global oceans. (d)-(f) As in (a)-(c), respectively, but for the tropical Pacific $\left(8^{\circ} \mathrm{S}-8^{\circ} \mathrm{N}, 120^{\circ} \mathrm{E}-70^{\circ} \mathrm{W}\right)$. The dotted line represents the TAO/TRITON in $(\mathrm{d})$ and (e) and represents the coverage without TAO/TRITON in (f). The numbers and coverages are based on monthly $2^{\circ} \times 2^{\circ}$ data, and a 12-month running filter is applied in plotting.

evaluated by data exclusion experiments when part of the data from those observing systems is withheld.

Most of the past evaluations have focused on the role of Argo floats and TAO/TRITON in the thermocline temperature and salinity in ocean reanalysis studies (e.g., Balmaseda et al. 2007; Oke and Schiller 2007;
Huang et al. 2008; Xue et al. 2017; Gasparin et al. 2015; Fujii et al. 2015). These studies indicated that the ocean reanalyses are impacted more by Argo observations than by TAO/TRITON observations, and both Argo and TAO/TRITON can improve the hindcasts for thermocline temperature and sea surface temperature (SST) at 
1-15-month lead time (Fujii et al. 2015). In particular, prediction for El Niño and Southern Oscillation (ENSO) in the tropical Pacific may potentially deteriorate due to reduced TAO/TRITON observations (Ji and Leetmaa 1997; Xue et al. 2017).

Among those studies, the impact of observations on SST analysis is less studied. The SST analysis critically depends on the number and area coverage of the observations near the ocean surface. Note that the area coverage of observations depends on the number of observations and the spatial resolution of an analysis, which is calculated as follows in this paper: 1) observations are gridded into $2^{\circ} \times 2^{\circ}$ boxes, 2) the area where a $2^{\circ} \times 2^{\circ}$ box contains observations is calculated, 3 ) the total ocean area without observations is calculated, and 4) the ratio of the areas in steps 2 and 3 is defined as the area coverage in the global ocean or tropical Pacific.

The depth of in situ SST observations varies from drifting buoys $(0.2-0.3 \mathrm{~m})$, moored buoys $(0.5-3 \mathrm{~m})$, and ship buckets, engine room intakes (ERIs), and hull contact sensors including thermosalinographs (TSGs) (1-10 m) (Reynolds et al. 2002; Lumpkin and Pazos 2007; Barale et al. 2010, 237-238; Matthews 2013). These ship and buoy observations from the world's oceans are collected and published in near-real time (Freeman et al. 2017) and widely used in SST analyses (Rayner et al. 2003; Ishii et al. 2005; Reynolds et al. 2007; Smith et al. 2008; Kennedy et al. 2011a,b; Huang et al. 2015a, 2017). Most recently, the near-surface (0-5-m depth) observations from Argo floats have been used in an SST analysis (Huang et al. 2017). These observations are usually processed into monthly or daily products due to their sparseness in spatial and temporal distributions. Therefore, the information of SST diurnal variability cannot be resolved, although the original observations do contain SST diurnal variation.

The number of ship observations from buckets and ERIs over the global oceans increased gradually from $10^{3}$ month $^{-1}$ in the 1860 s to $10^{5}$ month $^{-1}$ in the $1980 \mathrm{~s}$, decreased slightly in the 1990s (Huang et al. 2017), and remained steady over the 2000s to 2010s (Fig. 1a; solid black). The number of buoy observations from drifters and moorings increased rapidly from $10^{4}$ month $^{-1}$ in the 1980 s to $10^{6}$ month $^{-1}$ in the 2010 s. The number of Argo observations increased quickly from $10^{2}$ month $^{-1}$ in the 2000s to $10^{4}$ month $^{-1}$ in the 2010s (Fig. 1a; solid green). The area coverage of the in situ SST observations from ships, buoys, and Argo floats in the global oceans was approximately $10 \%$ in the 1860 s, increased to approximately $70 \%$ in the 1980 s (Huang et al. 2017), and remained at $65 \%-75 \%$ over the 2000 s and 2010 s (Fig. 1c; solid purple). Studies indicate that these increases in the number and coverage of observations have enhanced the reliability of the SST analyses in the modern periods since the 1980s (Kennedy et al. 2011a,b; Hirahara et al. 2014; Huang et al. 2015a).

The high number and coverage of the in situ SST observations in the recent decades (the 2000s and 2010s) are attributed to the increasing observations from Argo floats and buoys (Figs. 1a and 1b; solid green and solid red). The coverage of Argo SST increased from nearly zero in the early 2000 s to approximately $30 \%$ in the 2010s, and the coverage of buoy SSTs increased from approximately $20 \%$ in the early 2000 s to approximately $35 \%$ after the later 2000s (Fig. 1b; solid green and solid red). In contrast to the increase of Argo and buoy coverages, the ship SST coverage decreased from $60 \%$ in the early 2000s down to $50 \%$ in the 2010s (Fig. 1b; solid black), although the number of ship observations remained steady (Fig. 1a; solid black).

The changes in the partition and configuration of ship, buoy, and Argo observations may affect the global SST analyses including the climatology and trends, which are an important aspect for monitoring and assessment of the global ocean climate and climate change. The ship SST observations frequently took place along commercial shipping lanes and therefore the data coverage was lower in the central tropical Pacific (cf. Figs. 1b and 1e; solid black), the northern North Atlantic, the Arctic, and the Southern Ocean. In contrast, the SST observations from drifting buoys and Argo floats in the modern period after 2000 were relatively uniformly distributed over the global oceans and had a better coverage in the central tropical Pacific (cf. Figs. $1 \mathrm{~b}$ and 1e; solid red and solid green), the northern North Atlantic, and the Southern Ocean. In particular, the coverage of SST observations has been greatly improved by Argo floats and drifting buoys in the Southern Ocean in the past decades. However, it has not been clear how these changes in the observation coverage by different platforms affect the existing global and regional SST analyses. These are studied in this paper using two widely used SST analyses.

The rest of the paper is organized as follows: Two SST analysis systems, designed experiments, and evaluation datasets are described in section 2. The roles of buoy and Argo observations in the Extended Reconstructed SST version 5 (ERSSTv5; Huang et al. 2017) over 2000-16 are assessed in section 3. The role of the TAO and TRITON moorings in the tropical Pacific $\left(8^{\circ} \mathrm{S}-8^{\circ} \mathrm{N}, 120^{\circ} \mathrm{E}-70^{\circ} \mathrm{W}\right)$ is assessed using the monthly ERSSTv5 in section 4 and the daily Optimum Interpolation SST (OISST) (Reynolds et al. 2007) in section 5. Section 6 includes a summary and conclusions. Note that "ship" observations in this study represent the measurements from buckets, ERIs, 
hull contact sensors, and TSGs; and the "buoy" observations represent the measurements from both drifters and moorings including TAO/TRITON unless the buoy is specified as "drifting buoy" or "moored buoy."

\section{SST analysis systems, experiment design, and evaluation datasets}

\section{a. Monthly ERSSTv5}

The monthly ERSSTv5 (Huang et al. 2017) is used to assess the role of buoy (drifters and moorings including TAO/TRITON) and Argo observations. The details of ERSSTv5 are described in Huang et al. (2017) and the following is a brief summary: ERSSTv5 provides a monthly $2^{\circ} \times 2^{\circ} \mathrm{SST}$ analysis from 1854 to the present (the data between 2000 and 2016 are used in this study). ERSSTv5 uses ship, buoy, and Argo observations. The ship and buoy observations are from the International Comprehensive Ocean-Atmosphere Dataset (ICOADS) Release 3 (Freeman et al. 2017). The Argo observations of 0-5-m depth are retrieved from the Global Data Assembly Centre (GDAC; http://www.seanoe.org/data/ 00311/42182).

By taking the advantage of accurate buoy SSTs after the 1980s, the biases of ship SSTs after 1985 are corrected according to buoy observations, which enable the ERSSTv5 system to produce operational data without depending on the nighttime marine air temperature (NMAT; Rayner et al. 2003). The biases of ship SSTs between 1854 and 1985 are estimated as follows: 1) The biases of ship SSTs from 1854 to 2014 are calculated according to the NMAT. 2) The biases of ship SSTs derived from the NMAT from 1990 to 2010 are compared with those derived from buoy SSTs, and a near-constant offset of $0.077^{\circ} \mathrm{C}$ is identified. 3) The biases of ship SSTs derived from the NMAT between 1854 and 1985 are adjusted by subtracting $0.077^{\circ} \mathrm{C}$. 4) The adjusted biases over 1854 1985 are finally applied to the ship SSTs in ERSSTv5. The adjustment of the ship SST biases enables the consistent bias corrections of ship SSTs derived from the NMAT and buoy SSTs between 1990 and 2010. To maintain the same baseline from buoy SSTs as described above, the Argo SSTs are adjusted according to a mean difference of $0.03^{\circ} \mathrm{C}$ between buoy and Argo observations from 2000 to 2014. These adjustments applied to ship and Argo SSTs are intended to homogenize the observations from different types of instruments to represent the temperature at a nominal depth of $0.2 \mathrm{~m}$.

The bias-corrected SSTAs were then fitted to a maximum of 140 leading empirical orthogonal teleconnection functions (EOTs) (van den Dool et al. 2000; Smith et al. 2008). The appendix provides the details in ERSSTv5 reconstruction, and more details can be found in Huang et al. (2015a). As indicated in Huang et al. (2017, 2018), the spatial variabilities of SSTA become more realistic in ERSSTv5 than its previous versions in both the tropical and midlatitude oceans.

\section{b. Daily OISST}

To ensure the conclusions based on ERSSTv5 experiments, the daily OISST (DOISST) (Reynolds et al. 2007) is used to reassess the role of TAO, buoy (both drifters and moorings including TAO/TRITON), and Argo observations. One major difference between DOISST and ERSSTv5 is that DOISST has a finer resolution of daily $0.25^{\circ} \times 0.25^{\circ}$ and does not include Argo observations. Another major difference is that DOISST includes satellite AVHRR observations while ERSSTv5 does not.

The AVHRR observations provide a near-global coverage, but AVHRR-derived SSTs may contain systematic biases. The AVHRR SSTs are retrieved from the radiances measured in various wavelengths. The infrared instrument of AVHRR can only penetrate the top millimeters of the sea surface. Therefore, the AVHRR SSTs represent the skin temperature of the sea surface water, tend to be more variable and sensitive to diurnal heating, and may be different from the in situ SSTs measured by thermometers at a nominal depth of $0.2 \mathrm{~m}$. In addition, the AVHRR SSTs may be contaminated by clouds and continental aerosols and therefore exhibit systematic biases (Huang et al. 2015b).

The biases of AVHRR SSTs are corrected according to the available in situ observations from ships and buoys, after the biases of ship SSTs are corrected by subtracting $0.14^{\circ} \mathrm{C}$ from ship SSTs (Reynolds et al. 2007). The bias correction of AVHRR SSTs enables the AVHRR SSTs to be consistent with in situ observations. Therefore, the inclusion or exclusion of in situ observations from DOISST can impact the DOISST in the following two ways: 1) to directly change the number and spatial coverage of in situ SSTs in the same way as in ERSSTv5, and 2) to indirectly change the AVHRR SSTs by different bias corrections applied to AVHRR SSTs.

The daily biases of AVHRR SSTs (say 10 July 2017) are calculated as follows: First, the daily AVHRR and in situ SSTs are bin-averaged to a $2^{\circ} \times 2^{\circ}$ grid box. Second, the difference between AVHRR and in situ SSTs are calculated within a 15-day running window (say 3-17 July 2017), which is defined as AVHRR biases. Finally, the daily biases on $2^{\circ} \times 2^{\circ}$ grids are interpolated to $0.25^{\circ} \times 0.25^{\circ}$ grids and applied to AVHRR SST [see more details in Reynolds et al. (2007) and Huang et al. (2015b)]. By adjusting the biases of AVHRR SSTs, the DOISST represents the SSTs at a nominal depth of $0.2 \mathrm{~m}$. 
DOISST provides a daily analysis from September 1981 to the present (the data between 2000 and 2016 are used in this study). The daily $0.25^{\circ} \times 0.25^{\circ}$ data are averaged to monthly $2^{\circ} \times 2^{\circ}$ for the purpose of comparisons. The DOISST uses ship and buoy observations from an earlier version ICOADS Release 2.5 from September 1981 to December 2006 (Woodruff et al. 2011), and ship and buoy observations from the Global Teleconnection System after 2006.

\section{c. Experiment design}

To assess the individual role of buoy and Argo observations in the global SST analyses of ERSSTv5 in the recent decades, the following data exclusion experiments (Table 1) are designed by ingesting different combinations of observations with no drifting or moored buoys (nBUOY), no Argo floats (nARG), and both no buoys and no Argo floats (nBUOYnARG) in the global oceans. To assess the individual role of TAO/TRITON, buoy (both drifters and moorings), and Argo observations in the tropical Pacific, additional analysis experiments (Table 1) are designed by ingesting observations with no TAO/TRITON (nTAO), no drifting or moored buoys (nBUOY8), no Argo floats (nARG8), and both no buoys and no Argo floats (nBuoy8nARG8) in the tropical Pacific $\left(8^{\circ} \mathrm{S}-8^{\circ} \mathrm{N}, 120^{\circ} \mathrm{E}-70^{\circ} \mathrm{W}\right)$.

Similarly, DOISST (Reynolds et al. 2007) and its associated nTAO and nBUOY8 experiments (Table 2 ) are designed to compare the impacts of TAO/TRITON on the tropical Pacific. To assess the role of Argo in DOISST, an experimental DOISST is designed with Argo observations included (DOISSTwARG). The role of TAO/TRITON and buoy observations in the tropical Pacific is then reassessed in the experiments nTAOwARG and nBUOY8wARG by withholding TAO and buoy observations in the tropical Pacific (Table 2). It should be noted that all DOISST experiments are conducted at the native daily $0.25^{\circ} \times 0.25^{\circ}$ grids. The outputs of these experiments are later boxaveraged into monthly $2^{\circ} \times 2^{\circ}$ to compare with those of ERSSTv5 and its experiments.

\section{d. Evaluation datasets}

Monthly ERSSTv5, DOISST, and their associated experiments are used to assess the impacts of $\mathrm{TAO} /$ TRITON, buoy, and Argo observations on the global SST and ENSO events in the tropical Pacific. The quality of ERSSTv5, DOISST, and their associated experiments is assessed by root-mean-square difference (RMSD) against TAO/TRITON SSTs and independent European Space Agency (ESA) Climate Change Initiative (CCI) SST version 1.2 (Merchant et al. 2014).
TABLE 1. Monthly ERSSTv5 (v5) and its experiments.

\begin{tabular}{lc}
\hline \multicolumn{1}{c}{ Experiment } & \multicolumn{1}{c}{ Description } \\
\hline ERSSTv5 & Operational ERSSTv5 \\
nBUOY & As in v5, but excluding all drifting and \\
moored buoy SSTs in global oceans & As in v5, but excluding all Argo SSTs in \\
nARG & global oceans \\
nBUOYnARG & As in v5, but excluding all buoy and Argo \\
& SSTs in global oceans \\
nTAO & As in v5, but excluding TAO/TRITON \\
& mooring SSTs in $8^{\circ} \mathrm{S}-8^{\circ} \mathrm{N}, 120^{\circ} \mathrm{E}-70^{\circ} \mathrm{W}$ \\
nBUOY8 & As in v5, but excluding all buoy including \\
& TAO/TRITON SSTs in $8^{\circ} \mathrm{S}-8^{\circ} \mathrm{N}$, \\
nARG8 & $120^{\circ} \mathrm{E}-70^{\circ} \mathrm{W}$ \\
nBUOY8nARG8 & As in v5, but excluding Argo SSTs in \\
& $8^{\circ} \mathrm{S}-8^{\circ} \mathrm{N}, 120^{\circ} \mathrm{E}-70^{\circ} \mathrm{W}$ \\
As in v5, but excluding buoy and Argo \\
ERSSTv5nARG & SSTs in $8^{\circ} \mathrm{S}-8^{\circ} \mathrm{N}, 120^{\circ} \mathrm{E}-70^{\circ} \mathrm{W}$ \\
& As in v5, but excluding Argo (same as \\
nTAOnARG & nARG) \\
& As in ERSSTv5nARG, but excluding \\
& TAO/TRITON mooring SSTs in \\
$8^{\circ} \mathrm{S}-8^{\circ} \mathrm{N}, 120^{\circ} \mathrm{E}-70^{\circ} \mathrm{W}$
\end{tabular}

The daily SSTs from TAO/TRITON moorings are downloaded from the Pacific Marine Environmental Laboratory (PMEL; http://www.pmel.noaa.gov/gtmba) and processed into monthly averages for the comparison purpose. The CCI SST is a daily $0.05^{\circ} \times 0.05^{\circ}$ product from September 1991 to December 2015, which is derived from the Advanced Very High Resolution Radiometer (AVHRR) and Along-track Scanning Radiometer (ATSR). The derivation of CCI SST uses a reducedstate-vector optimal estimation algorithm, which does not require the calibrations from in situ observations and can represent the water temperature at $0.2-\mathrm{m}$ depth (Merchant et al. 2012). However, the ocean reanalysis data are used as a background field in the absence of observations. Therefore, CCI SST is thought to be almost independent from in situ observations. The CCI SST is averaged to monthly $2^{\circ} \times 2^{\circ}$ grids and compared with those experiments in section 3 .

\section{Impacts of buoy and Argo data on global SST in monthly ERSSTv5}

\section{a. SST trends}

To assess the impacts of buoy and Argo observations on monthly ERSSTv5 (or v5 for simplicity), the globally and annually averaged SSTAs (referenced to 1971-2000 averaged climatology) are calculated in v5, nBUOY, nARG, and nBUOYnARG (Table 1). These experiments show 
TABLE 2. Daily OISST and its experiments.

\begin{tabular}{lc}
\hline \multicolumn{1}{c}{ Experiment } & \multicolumn{1}{c}{ Description } \\
\hline DOISST & Operational DOISST \\
nTAO & As in DOISST, but excluding TAO/ \\
& TRITON mooring SSTs in $8^{\circ} \mathrm{S}-8^{\circ} \mathrm{N}$, \\
& $120^{\circ} \mathrm{E}-70^{\circ} \mathrm{W}$ \\
nBUOY8 & As in DOISST, but excluding all buoys \\
& including TAO/TRITON SSTs in $8^{\circ} \mathrm{S}-$ \\
& $8^{\circ} \mathrm{N}, 120^{\circ} \mathrm{E}-70^{\circ} \mathrm{W}$ \\
DOISSTwARG & As in DOISST, but including Argo SSTs \\
nTAOwARG & As in nTAO, but including Argo SSTs \\
nBUOY8wARG & As in nBOUY8, but including Argo SSTs \\
\hline
\end{tabular}

that the globally averaged SSTAs are very close in $v 5$ and nBUOY. The exception is that the SSTA is slightly higher in nBUOY than in v5 in 2002-05 (Fig. 2a; dotted red and solid black). The similar SSTAs in v5 and nBUOY suggest that the impact of excluding buoy observations is small due to including Argo observations. The reason for the small impact is that the coverage of ship + Argo observations is reasonably high (approximately 60\%), although it is $5 \%-10 \%$ lower than that of ship + buoy + Argo observations (Fig. 1c; solid green and solid purple). Likewise, the globally averaged SSTAs are almost same in v5 and nARG (Fig. 2a; solid black and dotted green), indicating that the impact of excluding Argo observations is small and overwhelmed by including the buoy observations over the global oceans. The reason for the small impact of Argo observations is that the coverage of ship + buoy observations remains high $(60 \%-70 \%)$ and is close to that of ship + buoy + Argo observations (65\%-75\%) (Fig. 1c; solid red and solid purple). However, when both Argo and buoy observations are excluded, the SSTA in nBUOYnARG (Fig. 2a; dotted black) clearly differs from v5 in 2001-05, 2007-08, 2010-13, and 2015-16, which is consistent with a large difference of coverages $(5 \%-25 \%)$ between ship alone and ship + buoy + Argo observations (Fig. 1c; solid black and solid purple).

The changes in those observations can affect the SSTA trends over 2000-16. The linear trends of annually and globally averaged SSTA are $0.151^{\circ} \pm 0.103^{\circ}, 0.142^{\circ} \pm$ $0.108^{\circ}, 0.149^{\circ} \pm 0.102^{\circ}$, and $0.114^{\circ} \pm 0.095^{\circ} \mathrm{C} \mathrm{decade}^{-1}$ in v5, nBUOY, nARG, and nBUOYnARG (Table 3; second row), respectively. These results suggest that the global SSTA trends are statistically significant (at $95 \%$ confidence level) not only in v5 but also in nBUOY, nARG, and nBUOYnARG when observations are reduced. The trend of global SSTA is robust even when both buoy and Argo observations are excluded in nBUOYnARG. However, the trend difference between 55 and nBUOYnARG is notable. The inclusion of buoy and Argo observations to a certain extent
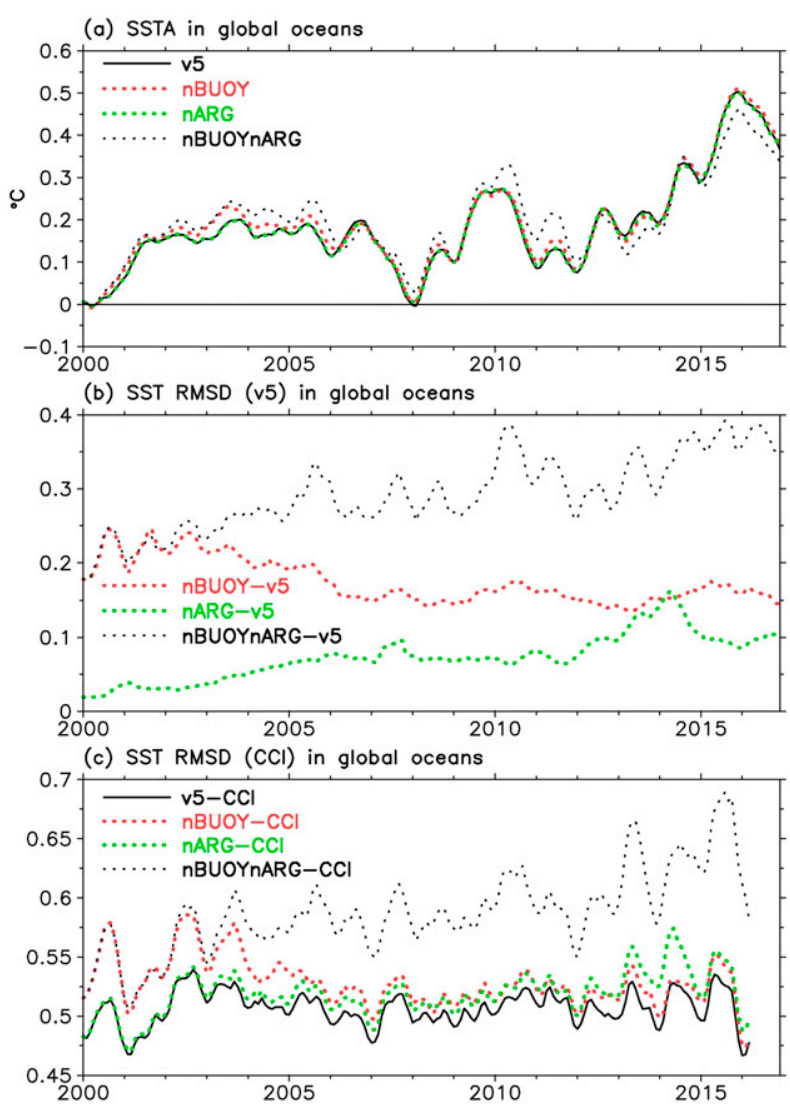

FIG. 2. (a) Globally averaged SSTAs in monthly ERSSTv5 (v5; solid black), nBUOY (dotted red), nARG (dotted green), and nBUOYnARG (dotted black). (b) SST RMSDs relative to v5 in nBUOY, nARG, and nBUOYnARG. (c) SST RMSDs relative to CCI in v5, nBUOY, nARG, and nBUOYnARG. A 5-month running filter is applied in plotting.

increases the positive trend of the global mean SST during the recent $17-y r$ period, in addition to the influence of the strong El Niño event of 2015/16 (Huang et al. 2016). Qualitatively, the warming trend of global SSTA in the recent 15-17 years (Karl et al. 2015; Hausfather et al. 2017; Huang et al. 2017) may not be associated with the increasing buoy and/or Argo observations.

The small impact of the individual type of buoy or Argo observations on globally averaged SSTA can be seen from the small trends of global SST differences between nBUOY and v5 (nBUOY - v5) and between nARG and v5 (nARG - v5). Calculations show that the trends of nBUOY $-\mathrm{v} 5\left(-0.009^{\circ} \pm 0.010^{\circ} \mathrm{C} \mathrm{decade}^{-1}\right)$ and $\mathrm{nARG}-\mathrm{v} 5\left(-0.002^{\circ} \pm 0.003^{\circ} \mathrm{C}\right.$ decade $\left.^{-1}\right)$ are not much significantly different from zero at $95 \%$ confidence level, indicating that the individual impact of buoy or Argo observations on globally averaged SSTA trend is statistically not significant. However, the global SSTA trend in nBUOYnARG $\left(0.114^{\circ} \pm 0.080^{\circ} \mathrm{C}\right.$ decade $\left.^{-1}\right)$ may be 
TABLE 3. Linear trends $\left({ }^{\circ} \mathrm{C}\right.$ decade $\left.^{-1}\right)$ of annually averaged SST over 2000-16 in monthly ERSSTv5, nBUOY, nARG, and nBUOYnARG. The uncertainty at the $95 \%$ confidence level is estimated by accounting for the first-order autoregressive effect on the degrees of freedom of the annually averaged SST series (von Storch and Zwiers 1999). The effective number $N_{e}$ of data length $N$ is reduced according to $N_{e}=N /(1+2 S)$, where $S=[(N-1) / N] C$ and $C$ is the lag-1 autocorrelation.

\begin{tabular}{lccrr}
\hline \hline & ERSSTv5 & nBUOY & nARG & nBUOYnARG \\
\hline $90^{\circ} \mathrm{S}-90^{\circ} \mathrm{N}$ & $0.151 \pm 0.103$ & $0.142 \pm 0.108$ & $0.149 \pm 0.102$ & $0.114 \pm 0.095$ \\
$60^{\circ}-90^{\circ} \mathrm{N}$ & $0.275 \pm 0.092$ & $0.277 \pm 0.093$ & $0.296 \pm 0.101$ & $0.292 \pm 0.102$ \\
$40^{\circ}-60^{\circ} \mathrm{N}$ & $0.240 \pm 0.133$ & $0.249 \pm 0.139$ & $0.244 \pm 0.126$ & $0.260 \pm 0.139$ \\
$20^{\circ}-40^{\circ} \mathrm{N}$ & $0.188 \pm 0.140$ & $0.212 \pm 0.135$ & $0.183 \pm 0.141$ & $0.201 \pm 0.145$ \\
$20^{\circ} \mathrm{S}-20^{\circ} \mathrm{N}$ & $0.199 \pm 0.196$ & $0.193 \pm 0.201$ & $0.199 \pm 0.196$ & $0.170 \pm 0.190$ \\
$40^{\circ}-20^{\circ} \mathrm{S}$ & $0.109 \pm 0.062$ & $0.074 \pm 0.070$ & $0.090 \pm 0.063$ & $-0.038 \pm 0.096$ \\
$90^{\circ}-40^{\circ} \mathrm{S}$ & $0.019 \pm 0.059$ & $-0.003 \pm 0.059$ & $0.022 \pm 0.062$ & $-0.010 \pm 0.064$ \\
\hline
\end{tabular}

significantly lower than v5 $\left(0.151^{\circ} \pm 0.086^{\circ} \mathrm{C}\right.$ decade $\left.^{-1}\right)$ because the trend of their SSTA difference of nBUOYnARGv5 $\left(-0.037^{\circ} \pm 0.036^{\circ} \mathrm{C}\right.$ decade $\left.^{-1}\right)$ appears significant at $95 \%$ confidence level. The significant difference between the trends of nBUOYnARG and v5 suggests an important impact of combined buoy and Argo observations on globally averaged SSTA trend, although their individual impact is small. The joined impact leads to a higher positive trend of global SST in the v5 data series, or a lower warming trend if both buoy and Argo observations are excluded over the recent 17 -yr analysis.

Despite the robustness of the warming trend in the globally averaged SSTA, the warming trend of regional SSTAs may be sensitive to the availability of observations (Table 3). In the South Hemisphere oceans, the SSTA trend decreases when buoy or/and Argo observations are excluded in the analyses. For example, in $40^{\circ}-20^{\circ} \mathrm{S}$ (Table 2; seventh row), the trends of the SSTA differences relative to v5 are $-0.036^{\circ} \pm 0.028^{\circ},-0.019^{\circ} \pm$ $0.013^{\circ}$, and $-0.147^{\circ} \pm 0.091^{\circ} \mathrm{C}$ decade $^{-1}$ in nBUOY-v5, nARG-v5, and nBUOYnARG-v5, respectively. Since these reductions in SST trends are statistically different from zero, they suggest a significant impact of Argo and buoy observations on the warming trend of the South Hemisphere oceans in the most recent 17 years. They also suggest that the significant trend difference between $\mathrm{v} 5$ and nBUOYnARG may mainly result from the expansion of the buoy or/and Argo observations from tropical to mid- and high-latitude Southern Ocean during the last 17 years.

\section{b. SST RMSD relative to ERSSTv5}

To assess the individual impact of buoy and Argo observations on monthly ERSSTv5 analysis, the RMSD relative to the ERSSTv5 (as the control run) is calculated over the global oceans over 2000-16 for the nBUOY, nARG, and nBUOYnARG experiments. The calculation shows that, for the nBUOY case, the RMSD decreases slightly from $0.20^{\circ} \mathrm{C}$ over $2000-05$ to $0.15^{\circ} \mathrm{C}$ over 2005-16 (Fig. 2b; dotted red). For the nARG case, the RMSD increases from near zero in 2000 to approximately $0.10^{\circ} \mathrm{C}$ in 2016 (Fig. 2b; dotted green). These changes in RMSDs in both nBUOY and nARG are clearly associated with the increasing Argo observations after 2005 (Figs. 1a and 1b; solid green), indicating an increasing impact of Argo floats to ERSSTv5 analysis. Overall, the RMSD is higher in nBUOY than in nARG over 2000-10, which is associated with the fact that the number and coverage of observations from buoys are higher than those from Argo floats (Figs. 1a and 1b; solid red and solid green). The higher RMSD in nBUOY indicates a larger impact of buoy than Argo observations.

The RMSDs in nBUOY and $\mathrm{nARG}$ are comparable after 2010 due to the comparable coverages of ship + Argo and ship + buoy observations (Fig. 1c; solid green and solid red), indicating that Argo observations become as important as buoy observations after 2010 . In contrast, when the observations from both Argo floats and buoys are excluded, the RMSD increases from approximately $0.20^{\circ} \mathrm{C}$ in 2000 to $0.35^{\circ} \mathrm{C}$ in 2016 (Fig. 2b; dotted black) due to a large decrease of observation coverage (Fig. 1c; solid black), indicating an important role of joined observations from buoys and Argo floats.

The higher impact of buoy observations can be seen from the RMSD of nBUOY relative to ERSSTv5 (200016) over the global ocean (Fig. 3a), particularly in the northwestern North Pacific and North Atlantic, the equatorial eastern Pacific, the Southern Ocean between $30^{\circ}$ and $60^{\circ} \mathrm{S}$, and the Arctic along the continental coasts. The spatial distribution of the RMSD of nARG (Fig. 3b) is very similar to that of nBUOY. However, the magnitude of RMSD drops from $0.16^{\circ} \mathrm{C}$ in nBUOY to $0.07^{\circ} \mathrm{C}$ in nARG for the global average. In contrast, the RMSD of nBUOYnARG (Fig. 3c) increases to $0.26^{\circ} \mathrm{C}$ for the global average with a similar spatial distribution in nBUOY (Fig. 3a) or nARG (Fig. 3b). 
(d) RMSD, v5-CCl, 2000-15

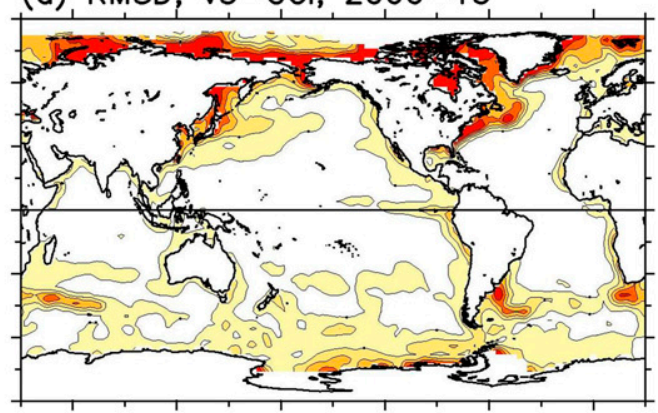

(a) RMSD, nBUOY-v5, 2000-16
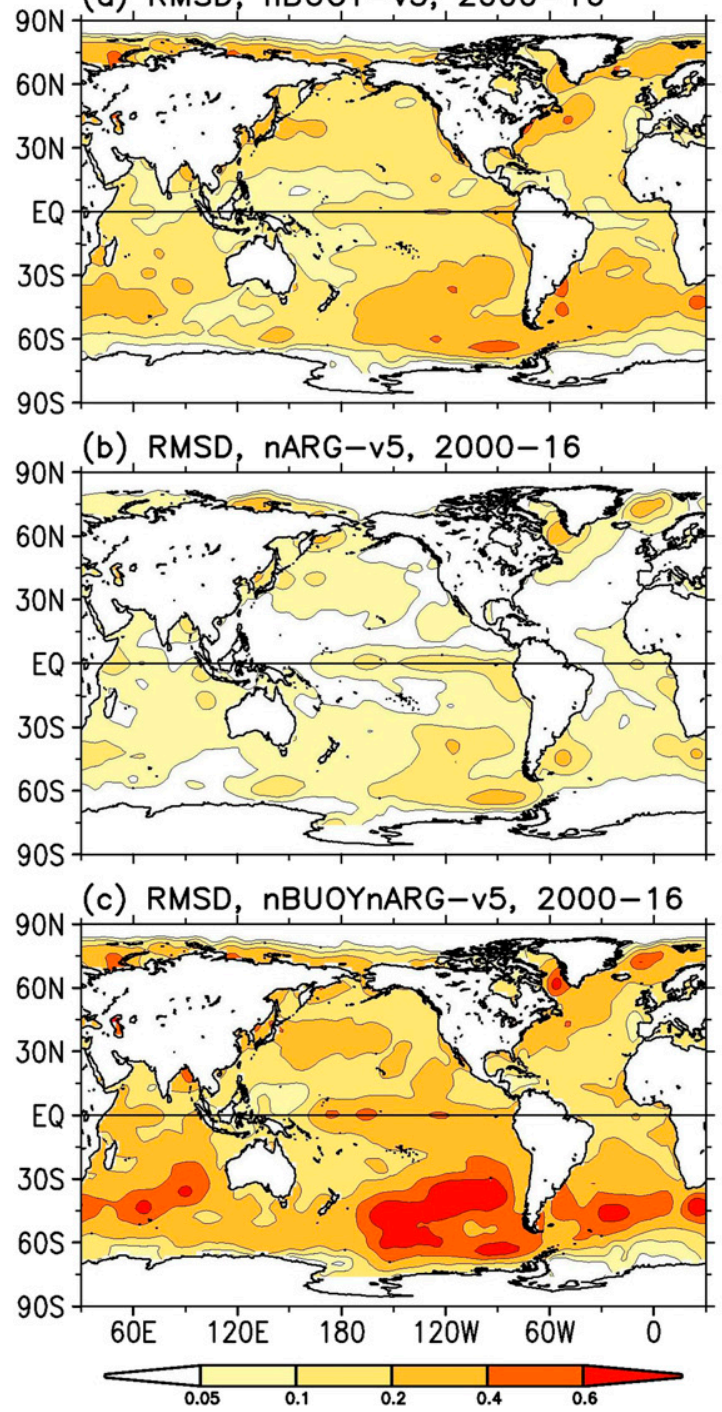

(e) RMSD, nBUOY-CCl, 2000-15

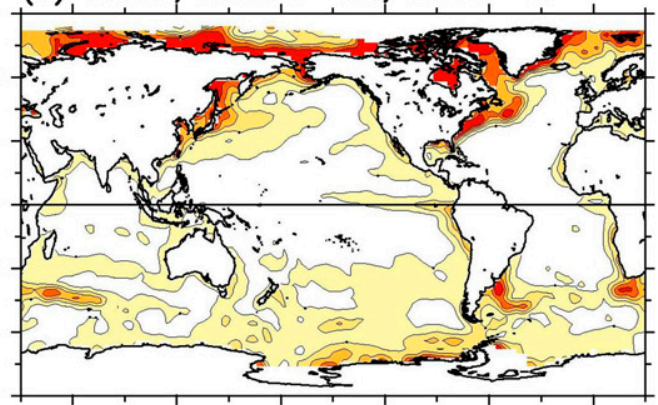

(f) RMSD, nARG-CCl, 2000-15

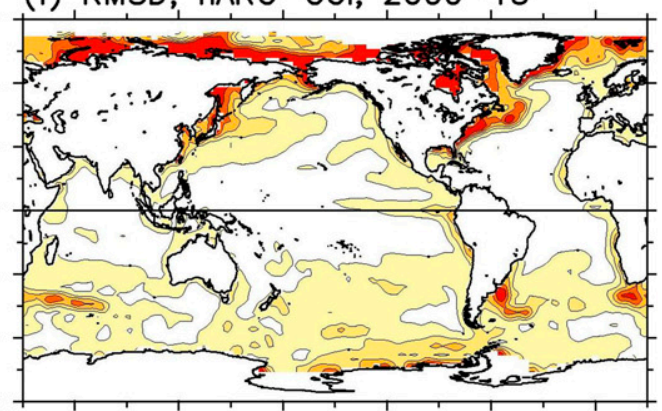

(g) RMSD, nBUOYnARG-CCI, 2000-15

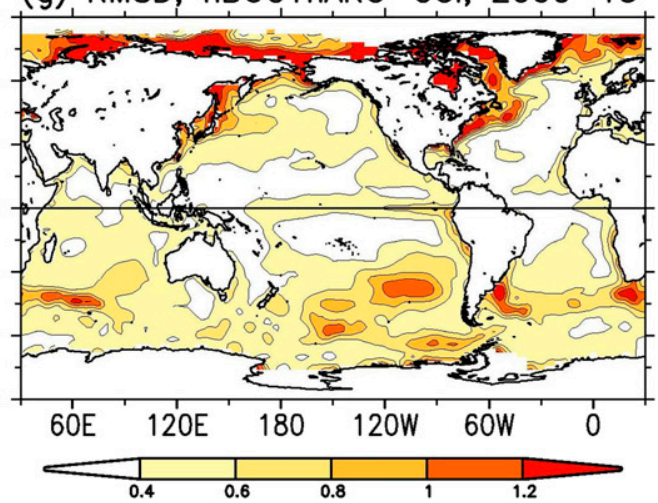

FIG. 3. (left) RMSDs relative to ERSSTv5 in (a) nBUOY, (b) nARG, and (c) nBUOYnARG and (right) RMSDs relative to CCI in (d) ERSSTv5, (e) nBUOY, (f) nARG, and (g) nBUOYnARG. Contours are $0.05^{\circ}, 0.1^{\circ}, 0.2^{\circ}, 0.4^{\circ}$, and $0.6^{\circ} \mathrm{C}$ in (a)-(c) and $0.4^{\circ}, 0.6^{\circ}, 0.8^{\circ}, 1.0^{\circ}$, and $1.2^{\circ} \mathrm{C}$ in $(\mathrm{d})-(\mathrm{g})$. 


\section{c. SST RMSD relative to satellite observations}

The impact of observations on the v5-based experiments is further assessed by independent CCI observations that are considered as valuable as in situ observations (Huang et al. 2018). The RMSDs in v5 and nARG are approximately $0.50^{\circ} \mathrm{C}$ over $2000-15$ (Fig. 2c; solid black and dotted green). The RMSD in nBUOY is approximately $0.55^{\circ} \mathrm{C}$ over $2000-03$, and decreases to approximately $0.50^{\circ} \mathrm{C}$ over $2005-15$ due to the increasing Argo observations (Fig. 2c; dotted red). In contrast, the RMSD in nBUOYnARG increases from approximately $0.55^{\circ} \mathrm{C}$ over $2000-03$ to approximately $0.65^{\circ} \mathrm{C}$ over $2014-15$ (Fig. 2c; dotted black) and differs slightly more from v5, nARG, and nBUOY over 2005-15 than over 2000-04. These comparisons to CCI observations indicate that the individual impact on SST analysis is relatively higher from buoy than from Argo observations, and that their individual impacts are much less than their joined impact.

Similar to those RMSDs relative to v5 in section $3 \mathrm{~b}$, the RMSDs relative to CCI between 2000 and 2010 are calculated. The RMSDs (Figs. 3d-g) are higher in the northwestern North Pacific and North Atlantic, the equatorial eastern Pacific, the Southern Ocean south of $30^{\circ} \mathrm{S}$, and the Arctic along the continental coasts. However, RMSDs are very close among four experiments, and their globally averaged RMSDs are $0.46^{\circ}, 0.47^{\circ}, 0.48^{\circ}$, and $0.54^{\circ} \mathrm{C}$ in v5, nBUOY, nARG, and nBUOYnARG, respectively. The higher RMSD in nBUOYnARG is mostly attributed to the Southern Ocean where the observations from ships are very sparse when buoy and Argo observations are excluded. The similar RMSDs among v5, nBUOY, nARG, and nBUOYnARG suggest that all these experiments are realistic.

\section{Impacts of TAO/TRITON on ENSO in monthly ERSSTv5}

The role of TAO/TRITON observations in ENSO in the tropical Pacific is assessed based on monthly ERSSTv5 and DOISST analyses. The impact of TAO/TRITON is assessed by withholding TAO/TRION observations while ship, drifting buoy, and Argo observations are included (sections 4a, 4b, 4c, and 5c). The assessment is repeated by withholding TAO/TRITON observations while only ship and drifting buoy are included in ERSSTv5 and DOISST (sections 4d, 5a, and 5b).

\section{a. Niño-3.4 region $\left(5^{\circ} \mathrm{S}-5^{\circ} \mathrm{N}, 120^{\circ}-170^{\circ} \mathrm{W}\right)$}

To assess the impact of TAO/TRITON, buoy (both drifters and moorings including TAO/TRITON), and Argo observations on ENSO activities in ERSSTv5based analyses, Fig. 4a shows the averaged SSTA in
Niño-3.4 region over 2000-16. The averaged Niño-3.4 in experiments nTAO, nBUOY8, nARG8, and nBUOY8nARG8 is very close to that in v5. The exception is that the Niño-3.4 in nBUOY8nARG8 is approximately $0.5^{\circ} \mathrm{C}$ warmer than that in v5 in later 2010 to 2011, and approximately $0.5^{\circ} \mathrm{C}$ colder in 2015 . In comparison with v5, the RMSD relative to v5 in Niño-3.4 region is less than $0.05^{\circ} \mathrm{C}$ in nTAO (Fig. 4b; dotted purple). The small RMSD suggests that the impact of TAO/TRITON observations on ERSSTv5 analysis is small, because the TAO/ TRITON coverage is very small (approximately 10\%) (Fig. 1e; dotted red) and the observations from ships, drifting buoys, and Argo floats (70\%-80\%) (Fig. 1f; dotted purple) have overwhelmed the TAO/TRITON observations.

When all buoy (both moored TAO/TRITON and drifting buoys) observations in the tropical Pacific are excluded in nBUOY8 (but Argo SSTs are included), the RMSD relative to $v 5$ in Niño-3.4 region increases slightly to $0.1^{\circ}-0.2^{\circ} \mathrm{C}$ over $2000-05$, and drops down to less than $0.1^{\circ} \mathrm{C}$ after 2005 (Fig. 4b; dotted red) due to the increasing Argo observations (Fig. 1e; solid green). The small RMSD after 2005 indicates that the impact of excluding buoy observations is reduced by including Argo observations. When Argo observations are excluded in nARG8 (but the buoy observations are included), the RMSD increases from near $0^{\circ} \mathrm{C}$ in 2000 to $0.15^{\circ} \mathrm{C}$ after 2010 (Fig. 4b; dotted green). The increase of RMSD is clearly associated with the increasing Argo observations that are excluded in nARG8. Overall, the impact is larger from buoy than Argo observations over 2000-05, less from buoy than Argo observations over 2010-16, and nearly equal over 2005-10.

In contrast, when both buoy and Argo observations are excluded in nBUOY8nARG8, the RMSD increases from $0.1^{\circ}-0.2^{\circ} \mathrm{C}$ over $2000-05$ to approximately $0.5^{\circ} \mathrm{C}$ over 2010-11 and 2015-16 (Fig. 4b; dotted black). The RMSD in nBUOY8nARG8 is much larger than the sum of those in nBUOY and nARG8, indicating that the impact of observation number and area coverage on ERSSTv5 analysis may not be linearly overlapped. These features of RMSDs in Niño-3.4 region represent how an SST analysis depends on observations in the tropical Pacific as indicated in Figs. 3a-c.

\section{b. Tropical Pacific region $\left(8^{\circ} \mathrm{S}-8^{\circ} \mathrm{N}, 120^{\circ} \mathrm{E}-70^{\circ} \mathrm{W}\right)$}

To assess the quality-dependence of ERSSTv5 analysis on TAO/TRITON, buoy, and Argo observations in the tropical Pacific $\left(8^{\circ} \mathrm{S}-8^{\circ} \mathrm{N}, 120^{\circ} \mathrm{E}-70^{\circ} \mathrm{W}\right)$, RMSDs are calculated in comparisons with TAO/TRITON observations. Figure $4 \mathrm{c}$ shows that the RMSDs in v5, nTAO, nBUOY8, and nARG8 are very close. The exception is that the RMSDs are slightly higher in nTAO and nBUOY8 than in v5 over 2000-05 when the 
(a) SSTA in NINO3.4 region

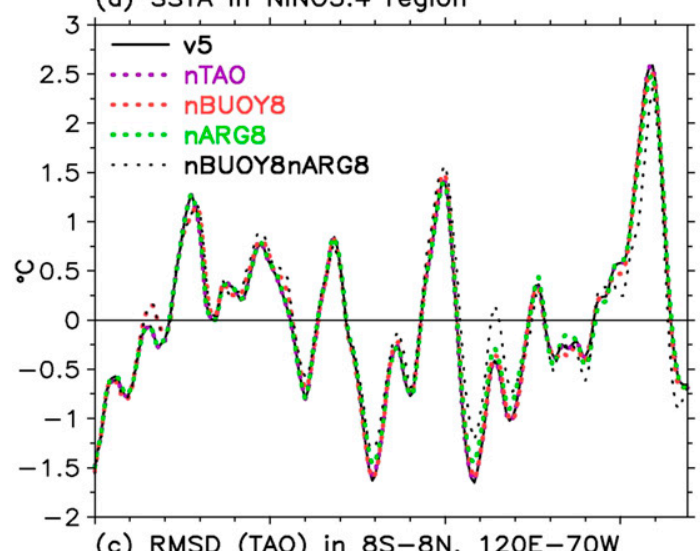

(c) RMSD (TAO) in $8 \mathrm{~S}-8 \mathrm{~N}, 120 \mathrm{E}-70 \mathrm{~W}$

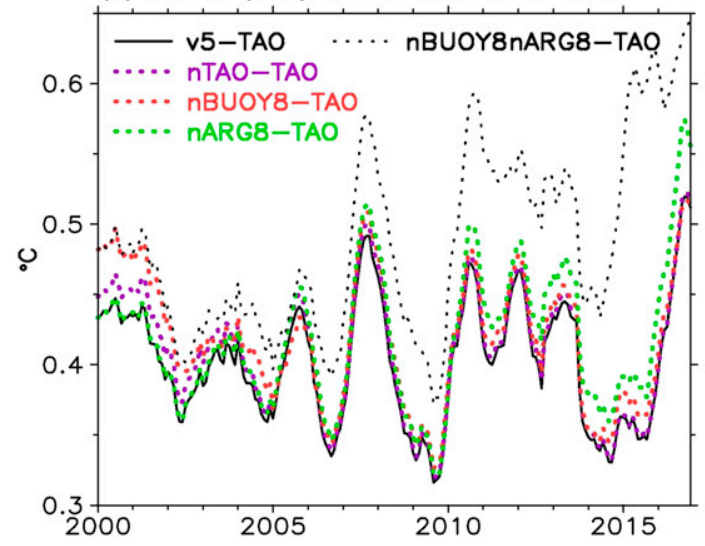

(b) RMSD in NINO3.4 region

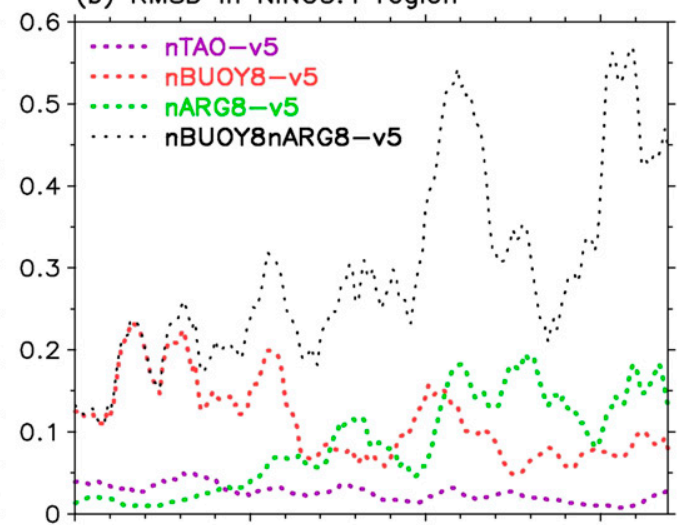

(d) RMSD $(\mathrm{CCl})$ in $8 \mathrm{~S}-8 \mathrm{~N}, 120 \mathrm{E}-70 \mathrm{~W}$

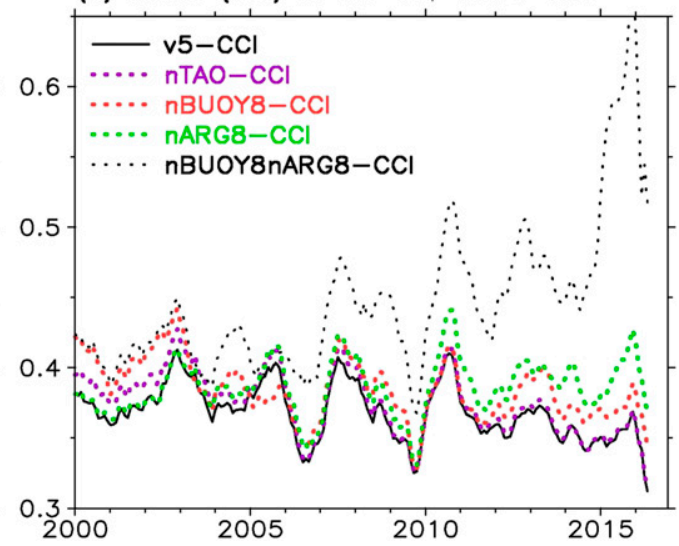

FIG. 4. (a) SSTAs in monthly ERSSTv5 (v5; solid black), nTAO (dotted purple), nBUOY8 (dotted red), nARG8 (dotted green), and nBUOY8nARG8 (dotted black) in the Niño-3.4 region $\left(5^{\circ} \mathrm{S}-5^{\circ} \mathrm{N}, 170^{\circ}-120^{\circ} \mathrm{W}\right)$. (b) RMSDs in nTAO, nBUOY8, nARG8, and nBUOY8nARG8 relative to v5 in the Niño-3.4 region. Also shown are SST RMSDs in v5, nTAO, nBUOY8, nARG8, and nTAOnARG8 relative to (c) TAO/TRITON (indicated by “TAO") and (d) CCI observations in the tropical Pacific $\left(8^{\circ} \mathrm{S}-8^{\circ} \mathrm{N}, 120^{\circ} \mathrm{E}-70^{\circ} \mathrm{W}\right)$. Running filters of 5 months in (a) and 12 months in (b)-(d) are applied in plotting.

number and coverage of Argo observations are low (Figs. 1d and 1e), and the RMSD is slightly higher in nARG8 than in v5 over 2010-16 when the number and coverage of Argo observations are high (Figs. 1d and 1e). In contrast, the RMSDs increase by $0.05^{\circ}-0.20^{\circ} \mathrm{C}$ in nBUOY8nARG8 over 2000-16 (Fig. 4c; dotted black), when both buoy and Argo observations are excluded. The similar features are found when SST analyses in v5, nTAO, nBUOY8, nARG8, and nBUOY8nARG8 are compared with independent SST observations from CCI over 2000-15 (Fig. 4d).

The above comparisons suggest that, when the recent observations from drifters, Argo floats, and ships are sustained, the impact of TAO/TRITON observations on the quality of monthly ERSSTv5 analysis is small. The reason for the small impact of TAO/TRITON is that the area coverage of TAO/TRITON observations $(5 \%-$ $10 \%$; Fig. 1e; dotted red) is much smaller than that of other in situ observations $(65 \%-75 \%)$. Note, however, that the number of the observations from TAO/TRITON is dominant and higher than those from ships and Argo floats (Fig. 1d), and TAO/TRITON's impact on higherfrequency (higher than monthly discussed in this section) SST analyses may be important and not as small as in these monthly SST analyses here.

Overall, the impact of buoys is slightly larger than Argo floats in the tropical Pacific over 2000-05 when the number of Argo floats is lower, but becomes slightly smaller over 2010-16 when the number and area coverage of Argo floats are higher. These features are consistent with those in Niño-3.4 region discussed in section $4 \mathrm{~b}$.

\section{c. An example of El Niño and La Niña}

The impacts of TAO/TRITON, buoy, and Argo observations on the monthly ERSST analysis in the tropical Pacific can clearly be seen in the El Niño event in 
(a) ERSSTv5, Nov2015
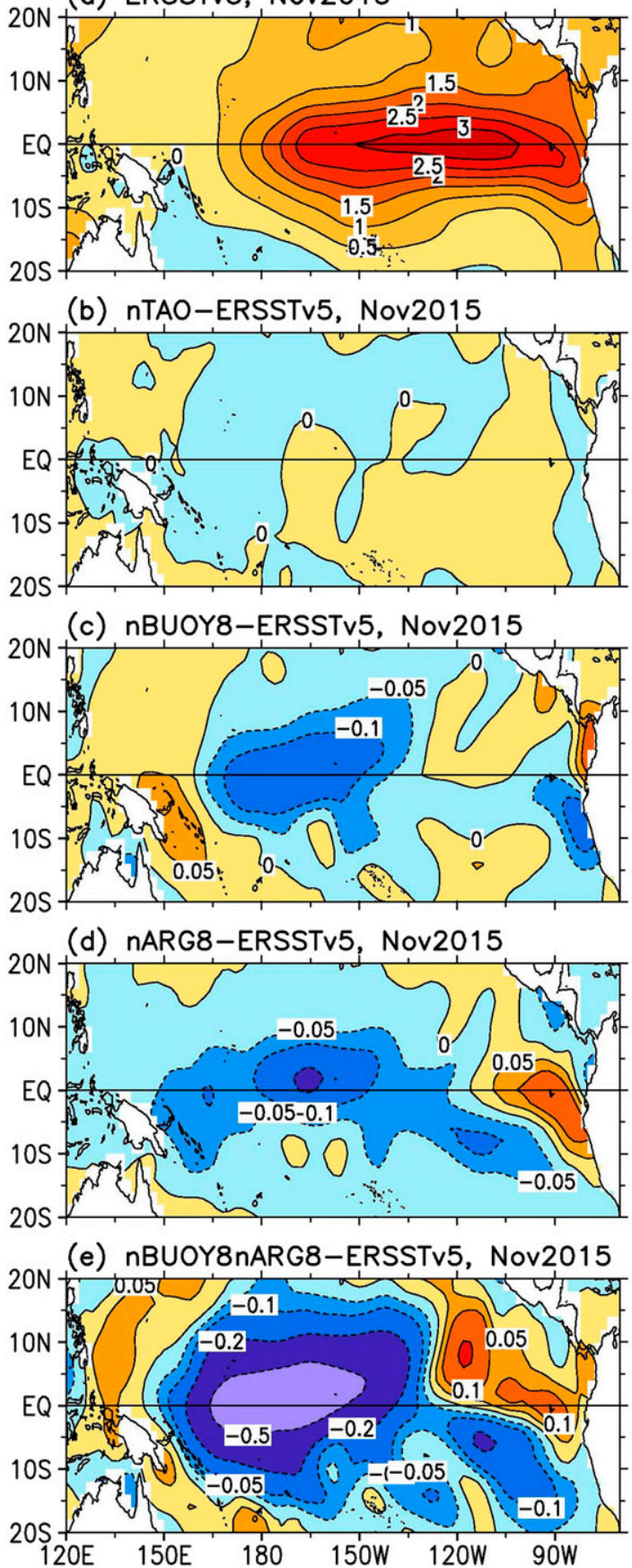

(f) ERSSTv5, Jan2011

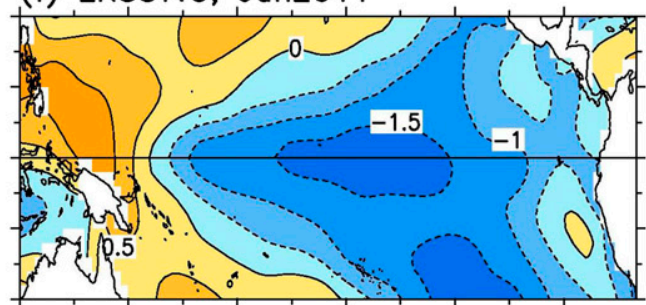

(g) nTAO-ERSSTV5, Jan2011

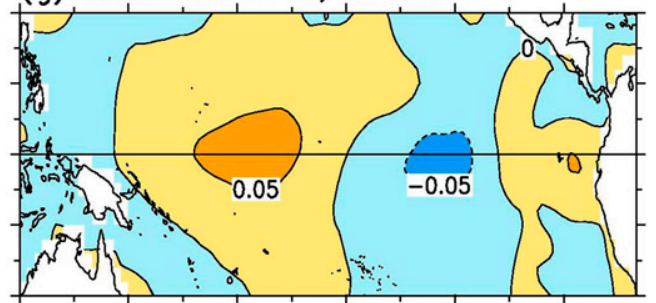

(h) nBUOY8-ERSSTv5, Jan2011
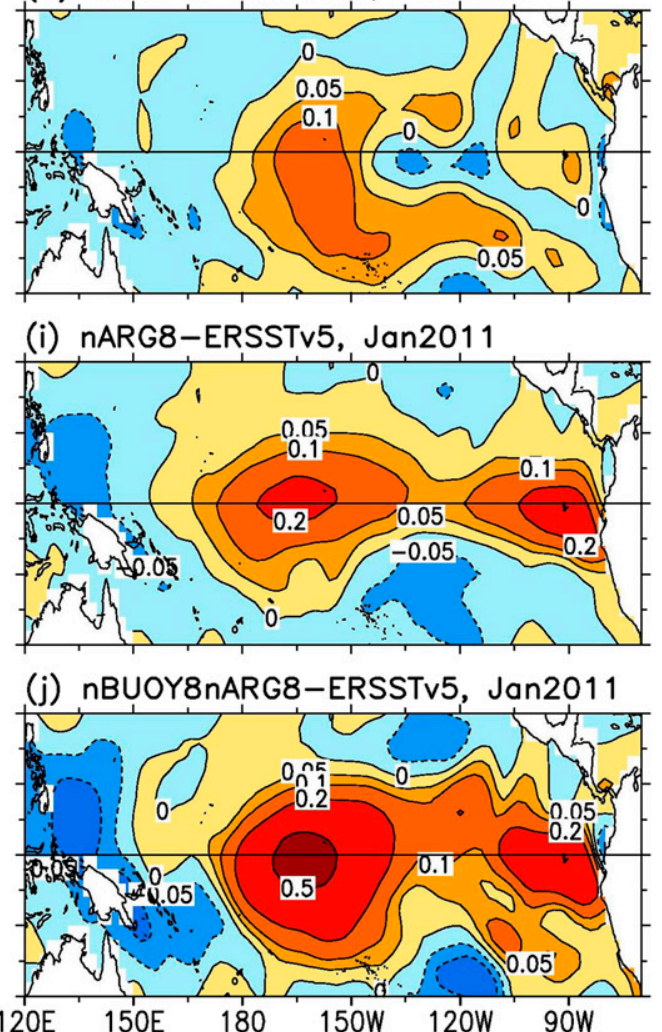

FIG. 5. (a) SSTA in ERSSTv5 and SSTA difference in (b) nTAO, (c) nBUOY8, (d) nARG8, and (e) nBUOY8nARG8 relative to ERSSTv5 in November 2015. (f)-(i) As in (a)-(e), respectively, but for SSTA in January 2011. Contour intervals are $0.5^{\circ} \mathrm{C}$ in (a) and (f), and contours are $0^{\circ}, \pm 0.05^{\circ}, \pm 0.1^{\circ}, \pm 0.2^{\circ}$, and $\pm 0.5^{\circ} \mathrm{C}$ in (b)-(e) and (g)-(j).

November 2015 (Fig. 5a) and La Niña event in January 2011 (Fig. 5f). Similar features are found but have not been discussed here for the El Niño event in January 2010 and La Niña event in January 2008. The 2014-16 El Niño event is one of the strongest events on record (Huang et al. 2016), and the 2010-12 La Niña event is one of the strongest La Niña events (Boening et al. 2012; Zhang et al. 2013). Our experiments show that the impacts of excluding $\mathrm{TAO} /$ TRITON observations from these two events are very small (Figs. 5b and 5g), indicating that TAO/TRITON 
observations are overwhelmed by other types of observations because of the low TAO/TRITON coverage at monthly time scale (Fig. 1e, dotted purple). It should be noted, however, that the impact of TAO/TRITON in the La Niña event in January 2011 is visible, albeit small $\left( \pm 0.05^{\circ} \mathrm{C}\right.$; Fig. $\left.5 \mathrm{~g}\right)$; this is associated with a relatively lower coverage of drifting buoys and will be discussed further in sections $4 \mathrm{~d}, 5 \mathrm{a}$, and $5 \mathrm{~b}$.

When buoy (both drifters and moorings including TAO/TRITON; Figs. 5c and 5h) or Argo (Figs. 5d and 5i) observations are excluded in the tropical Pacific, the SSTA differences from v5 are small $\left(0.1^{\circ}-0.2^{\circ} \mathrm{C}\right)$. The similar magnitude of SSTA difference suggests that the impacts on these El Niño and La Niña events from buoy and Argo observations are nearly equal. When both buoy and Argo observations are excluded (Figs. 5e and 5j), however, the SSTA differences become large in the central $\left(0.5^{\circ} \mathrm{C}\right)$ and eastern $\left(0.2^{\circ} \mathrm{C}\right)$ tropical Pacific, indicating a large impact of joined buoy and Argo observations on ERSSTv5 analysis during ENSO events.

A common feature of these data exclusion experiments is that the strength of El Niño and La Niña weakens when parts of the observations from buoys or Argo floats are excluded. This strongly indicates the importance of both buoy and Argo observations in accurately representing the SST analyses associated with ENSO activities.

\section{d. Influence of Argo observations on ENSO events}

The discussion in previous section $4 \mathrm{c}$ shows that the impact of TAO/TRITON observations on ENSO in monthly ERSSTv5 is small in the tropical Pacific, because TAO/TRITON observations are overwhelmed by ship, drifting buoy, and Argo observations. One may ask whether the impact of TAO/TRITON becomes large when Argo observations are excluded as in monthly ERSSTv4 and daily DOISST. To test the influence of Argo observations, the analyses ERSSTv5, nTAO, and nBUOY8 are repeated in the experiments ERSSTv5nARG (same as nARG), nTAOnARG, and nBUOY8nARG, respectively (Table 1) by excluding Argo observations over the global oceans.

When Argo observations are excluded, the data coverage decreases by $10 \%-20 \%$ (Fig. 1f, solid red and solid purple) but remains reasonably high. Therefore, the SST does not change much in the tropical Pacific as discussed in section 4b. The SSTA in nARG without Argo observations is very close to that in the ERSSTv5 with Argo observations. For example, the spatial distributions of the El Niño event in November 2015 (Fig. 6a) and La Niña event in January 2011 (Fig. 6d) are very close to those with Argo observations (Figs. 5a and 5f), although the strengths (say, $3^{\circ}$ and $-1.5^{\circ} \mathrm{C}$ contour area) become slightly weaker.
When TAO/TRITON observations are further excluded, the SST change relative to $\mathrm{nARG}$ remains small in the El Niño event in November 2015 (Fig. 6b), which is ignorable in comparison with that when all buoy observations are excluded (Fig. 6c). In contrast, the SST changes by approximately $\pm 0.1^{\circ} \mathrm{C}$ in the La Niña event in January 2011 (Fig. 6e) when TAO/TRITON observations are excluded, which is almost half of that (Fig. 6f) when all buoy observations are excluded in the tropical Pacific. The increased impact of TAO/TRITON on the La Niña event suggests the importance of TAO/TRITON because of the low coverage of drifting buoy when Argo observations are not included. One may further ask why the impact of TAO/TRITON is ignorable for the El Niño events while it is not ignorable (although it is small) for the La Niña events. The reason for the different impacts of TAO/TRITON on El Niño and La Niña events is largely associated with the difference in the drifting buoy coverage in the tropical Pacific during these two events, as mentioned previously in section $4 \mathrm{c}$. The coverage of drifting buoys is associated with the trade winds and related equatorial divergent Ekman flows that are strongly coupled with El Niño and La Niña activities, which will be discussed further in section $5 \mathrm{~b}$.

\section{Impacts of TAO/TRITON on daily OISST}

\section{a. Impacts of TAO/TRITON on El Niño and La Niña events}

The impacts of TAO/TRITON observations on the SST in the tropical Pacific, however, may vary in different analysis systems, because the number and area coverage vary at different time and spatial scales. Therefore, the DOISST and its associated experiments nTAO and nBUOY8 (Table 2) are analyzed here. The RMSD between nTAO and DOISST (Fig. 7; dotted red) is calculated in the Niño- 4 region $\left(5^{\circ} \mathrm{S}-5^{\circ} \mathrm{N}, 160^{\circ} \mathrm{E}-\right.$ $\left.150^{\circ} \mathrm{W}\right)$. The selection of the Niño-4 region is to better quantify the impact of TAO/TRITON on DOISST, while the impact is relatively small in Niño-3.4 and Niño-3 regions and will be discussed later in this subsection. The calculation shows that the RMSD is generally less than $0.1^{\circ} \mathrm{C}$, which looks consistent with that between monthly nTAO and ERSSTv5 (Fig. 4b; dotted purple). However, spikes of $0.2^{\circ}-0.3^{\circ} \mathrm{C}$ in the RMSD between nTAO and DOISST are found at time periods in January 2008 and January 2011 (Fig. 7, dotted red) when two La Niña events reach their mature phases (Fig. 4a). The magnitude of these spikes is no longer small in comparison with that between nBUOY8 and DOISST (Fig. 7, solid green). These spikes suggest that the impact of TAO/TRITON is large on these two La Niña events but small on the 
(a) nARG, Nov2015
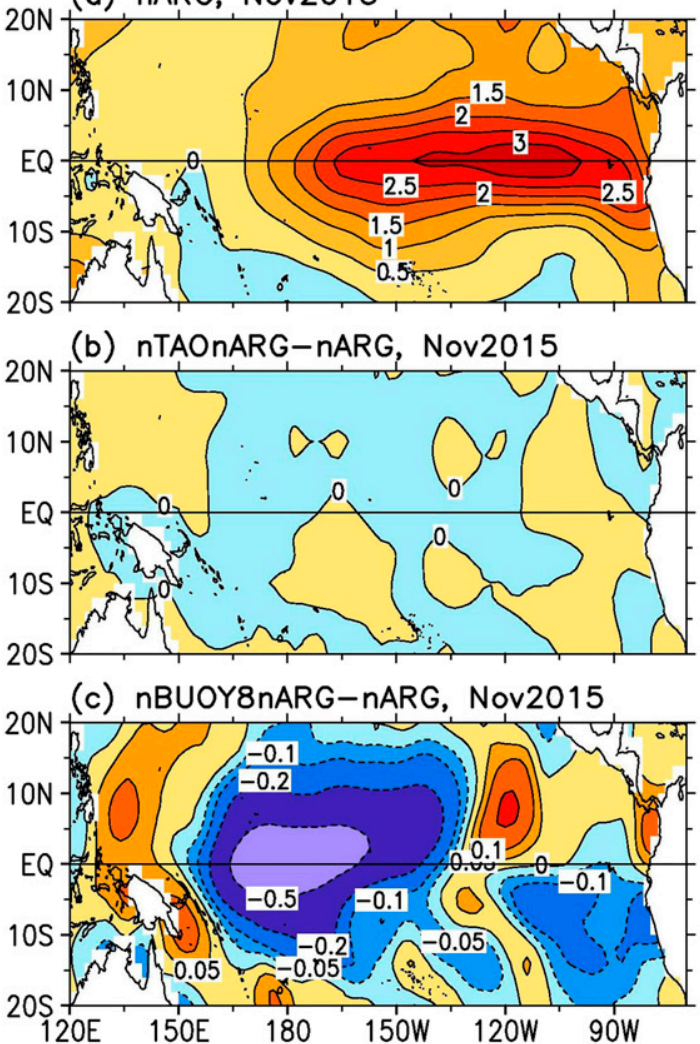

(d) nARG, Jan2011

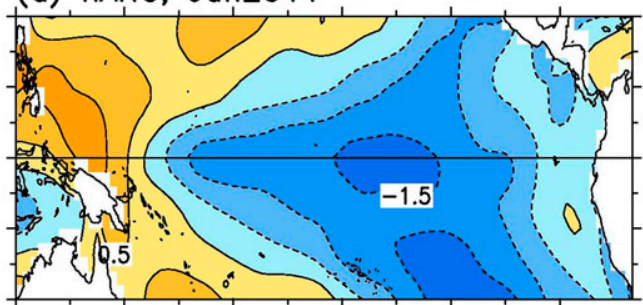

(e) nTAOnARG-nARG, Jan2011

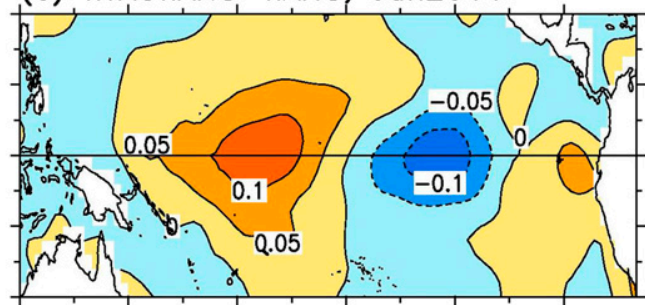

(f) nBUOY8nARG-nARG, Jan2011

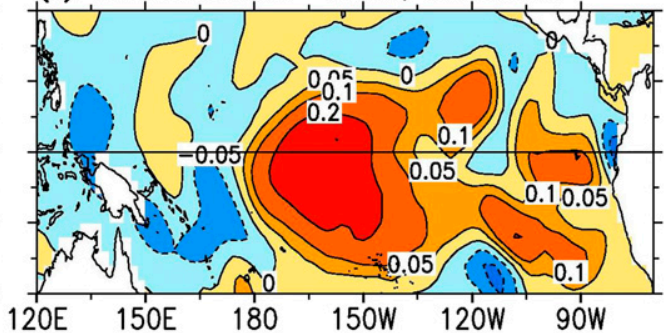

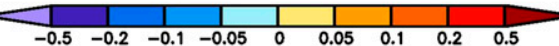

FIG. 6. (a) SSTA in nARG and SSTA difference in (b) nTAOnARG and (c) nBUOY8nARG relative to nARG in November 2015. (d)-(f) As in (a)-(c), respectively, but for January 2011. Contour intervals are $0.5^{\circ} \mathrm{C}$ in (a) and (d), and contours are $0^{\circ}, \pm 0.05^{\circ}, \pm 0.1^{\circ}, \pm 0.2^{\circ}$, and $\pm 0.5^{\circ} \mathrm{C}$ in (b), (c), (e), and (f).

El Niño events of 2010 and 2015 and during the normal years in DOISST, which needs to be explained further.

Studies have shown that the strength and spatial distribution of El Niño and La Niña events differ between monthly ERSSTv5 and daily DOISST (Huang et al. 2013,

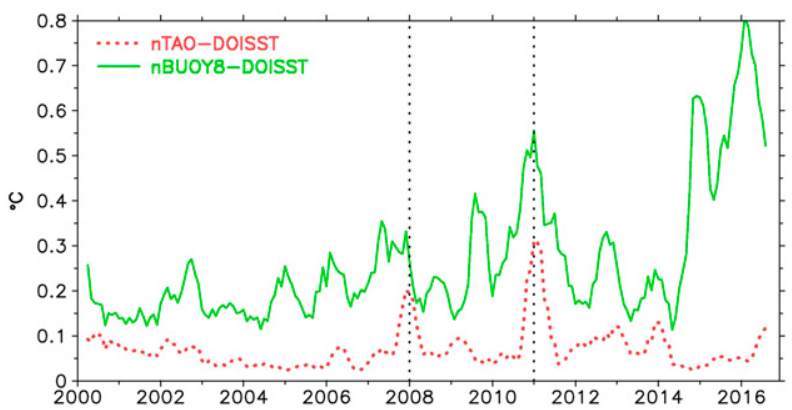

FIG. 7. RMSDs between daily nTAO and DOISST (dotted red) and between daily nBUOY8 and DOISST (solid green) in the Niño-4 region. A 5-month running filter is applied in plotting. January 2008 and 2011 are indicated by vertical dotted lines. 2015b). The difference is largely associated with the algorithm in correcting the biases in AVHRR-derived SST within a 15-day window in DOISST. For example, the El Niño event in November 2015 (La Niña in January 2011) is slightly stronger (weaker) in DOISST (Figs. 8a and 8d) than in ERSSTv5 (Figs. 5a and 5f). The $3^{\circ} \mathrm{C}$ SSTA contour extends more westward in DOISST than ERSSTv5, and the $-1{ }^{\circ} \mathrm{C}$ SSTA contour in the La Niña in January 2011 extends less westward in DOISST than in ERSSTv5. Note that DOISST has resolutions of daily and $0.25^{\circ} \times$ $0.25^{\circ}$ grid, while ERSSTv 5 has resolutions of monthly and $2^{\circ} \times 2^{\circ}$ grid. However, these differences should not affect our discussion on the relative impact of TAO/TRITON and buoy observations within DOISST system.

By excluding TAO/TRITON observations, the SST difference between nTAO and DOISST in the El Niño event in November 2015 is negligible (Fig. 8b) in comparison with that $\left(-0.5^{\circ} \mathrm{C}\right)$ between nBUOY8 and DOISST (Fig. 8c) when buoy observations are excluded in the tropical Pacific. The negligible difference between 
(a) DOISST, Nov2015

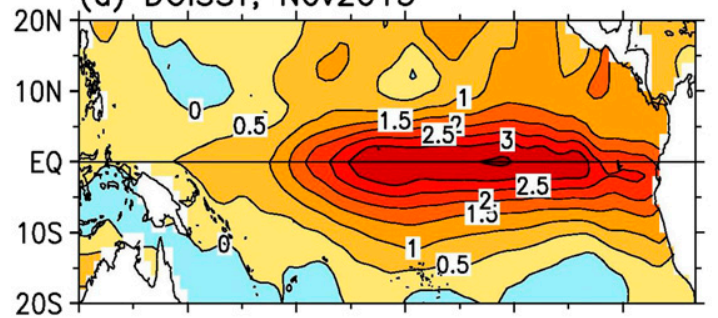

(b) nTAO-DOISST, Nov2015
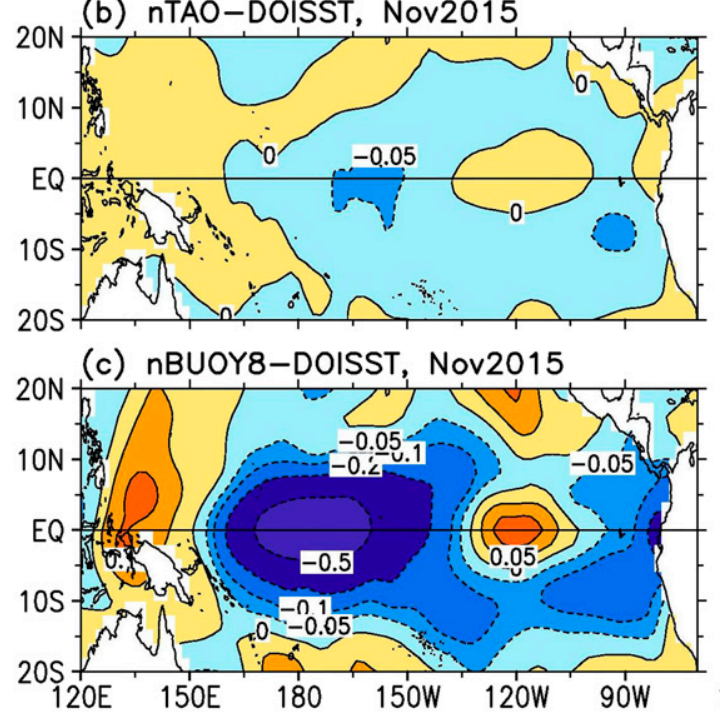

(d) DOISST, Jan2011

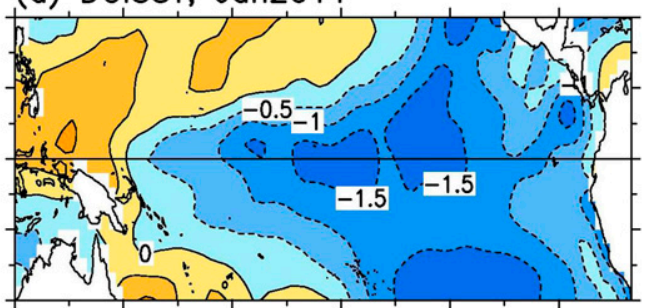

(e) nTAO-DOISST, Jan2011

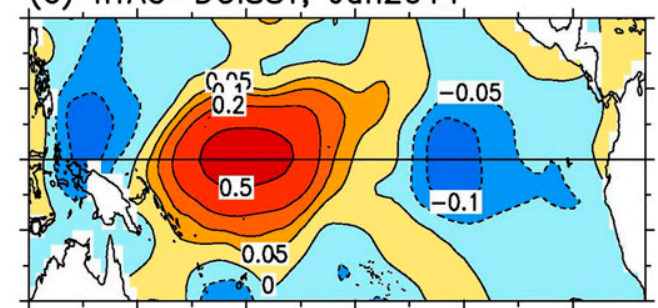

(f) nBUOY8-DOISST, Jan2011

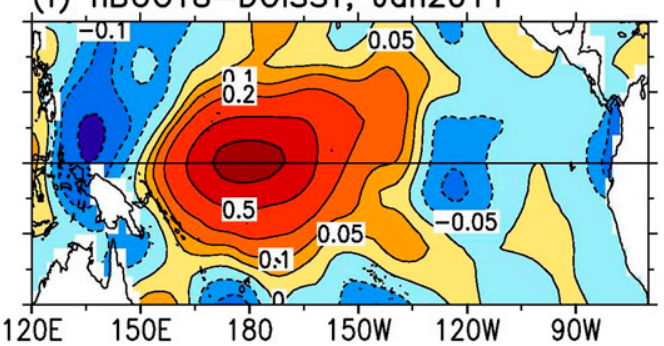

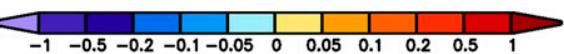

FIG. 8. (a) SSTA in DOISST and SSTA difference in (b) nTAO and (c) nBUOY8 relative to DOISST in November 2015. (d)-(f) As in (a)-(c), respectively, but for SSTA in January 2011. Contour intervals are $0.5^{\circ} \mathrm{C}$ in (a) and (d), and contours are $0^{\circ}, \pm 0.05^{\circ}, \pm 0.1^{\circ}, \pm 0.2^{\circ}$, and $\pm 0.5^{\circ} \mathrm{C}$ in (b), (c), (e), and (f). The DOISST data are boxaveraged to monthly $2^{\circ} \times 2^{\circ}$ values for the purpose of comparing with ERSSTv5.

nTAO and DOISST indicates that the impact of TAO/ TRITON on El Niño events is small in DOISST, which is consistent with that in ERSSTv5 (Fig. 5b). In contrast, the difference between nTAO and DOISST in the La Niña in January 2011 is as large as $+0.5^{\circ} \mathrm{C}$ (Fig. 8e), which is approximately half the difference of that between nBUOY8 and DOISST (Fig. 8f). The large difference between nTAO and DOISST indicates that the impact of TAO/TRITON on La Niña events is crucial in daily DOISST, and is more evident than that in monthly ERSSTv5 (Fig. 5g).

It should be noted that the SST differences by removing TAO stretch to $150^{\circ} \mathrm{E}$ near in DOISST experiments (Figs. 8e and 8f) but are confined mostly east of the date line in ERSSTv5 experiments (Figs. 6e and 6f). This explains why the larger impact is found in Niño-4 in DOISST and Niño-3.4 in ERSSTv5 experiments. In addition, these experiments clearly show that the strengths of El Niño and La Niña reduce when buoy or TAO/TRITON observations are excluded in the DOISST system, which is consistent with those discussed in the monthly ERSSTv5 system in section $4 \mathrm{~d}$.

\section{b. Coverages of TAO/TRITON and drifting buoys}

To detect why the impact of TAO/TRITON on La Niña events in DOISST is different from that in ERSSTv5, the daily area coverages of TAO/TRITON and drifting buoys are calculated (Fig. 9). The calculation of daily coverages uses the observations within a 15-day running window, since the biases of AVHRR SST are corrected within a 15-day window and DOISST is strongly dependent on the bias correction (Huang et al. 2013, 2015b). Figure 9 shows that the daily area coverage of TAO/TRITON (dotted red) is approximately $10 \%$ before 2012 and drops to approximately $5 \%$ over 2012-16, which is comparable with its monthly coverage (Fig. 1e; dotted red). The comparable area coverages of TAO/TRITON in daily and monthly time scales are 


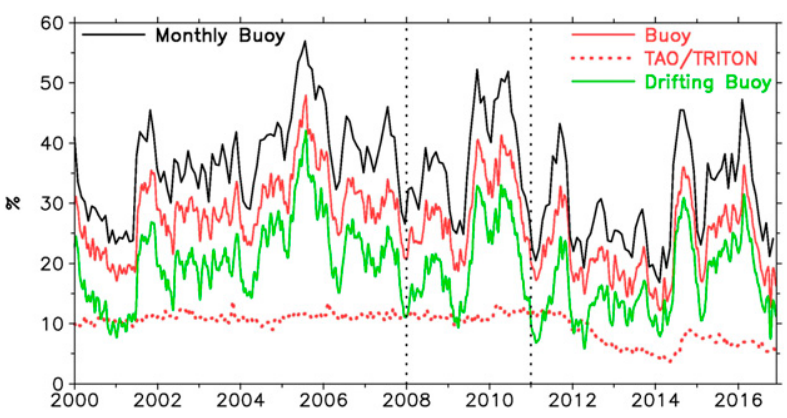

FIG. 9. Daily area coverage (\%) of observations in a 15-day window from buoys (TAO/TRITON and drifting buoy; solid red), TAO/TRITON only (dotted red), and drifting buoys only (solid green) in the tropical Pacific $\left(8^{\circ} \mathrm{S}-8^{\circ} \mathrm{N}, 120^{\circ} \mathrm{E}-70^{\circ} \mathrm{W}\right)$. A 15 -day running filter is applied in plotting. The monthly coverage of buoys (solid black) in Fig. 1e is overlapped. January 2008 and 2011 are indicated by vertical dotted lines.

attributed to the nature of moorings at fixed geographic locations; thus, spatial coverage is similar in daily and monthly frequencies. In contrast, the coverage of buoy observations is $5 \%-10 \%$ lower in daily DOISST (Fig. 9; solid red) than in monthly ERSSTv5 (Fig. 9; solid black).

The lower coverage of buoy observations in DOISST is associated with a lower coverage of drifting buoys, since the coverage of moored buoys from TAO/TRITON does not change much in DOISST and ERSSTv5. The lower coverage of drifting buoy is generally associated with a higher time resolution of one day in DOISST, since the total number of observations from drifting buoys is distributed among different days within a month. Note that the coverage is calculated within a 15day window and therefore the coverage is reduced but not dramatically. Furthermore, the lower coverage of drifting buoy in DOISST is affected by the strength of the equatorial divergent flows driven by the trade winds. During El Niño events (e.g., January 2010 and November 2015), the trade winds and therefore the divergent flows become weaker (Philander 1990; Huang et al. 2012; L'Heureux et al. 2017), so the drifting buoys can stay in the tropical oceans for a longer period, and therefore the area coverage is higher (Fig. 9; solid green). During La Niña events (e.g., January 2008 and January 2011), in contrast, the trade winds and divergent flows become stronger; the drifting buoys can only stay in the tropical oceans for a shorter period, and therefore the area coverage of drifting buoy becomes lower (Fig. 9; solid green).

When the coverage of drifting buoys is so low that it is less than or comparable to the coverage of TAO/TRITON, the exclusion of TAO/TRITON can have a large impact on the SST analysis in the tropical Pacific. For example, the coverage of drifting buoys in the La Niña event in January 2011 is low and less than that of TAO/TRITON (Fig. 9; solid green and dotted red). Therefore, the impact of TAO/TRITON is large on daily DOISST (Fig. 8e). Similarly, a large impact of TAO/TRITON on the La Niña in January 2008 is found in daily DOISST, while the impact is small in monthly ERSSTv5.

In contrast, when the coverage of drifting buoys is high, the contribution of TAO/TRITON to the SST analysis becomes small in the tropical Pacific. For example, the coverage of drifting buoys in the El Niño event in November 2015 is much higher than that of TAO/TRITON (Fig. 9; solid green and dotted red). Therefore, the impact of TAO/TRITON on the El Niño event in November 2015 is negligible (Fig. 8b). Similarly, the impact of TAO/TRITON on the El Niño event in January 2010 is small.

\section{c. Role of Argo observations in DOISST}

Our experiments have shown that the impact of $\mathrm{TAO} /$ TRITON on the La Niña event in January 2011 is evident (Figs. 6e and 8e), when SSTs from Argo floats are not included in monthly ERSSTv5 and daily DOISST. In contrast, the impact of TAO/TRITON becomes very small (Fig. 5g) when SSTs from Argo floats are included in monthly ERSSTv5. To further verify the role of Argo in SST analysis, an additional set of DOISST experiments that include Argo observations (DOISSTwARG; Table 2) was designed.

These experiments show that the impact of $\mathrm{TAO} /$ TRITON on the La Niña event in January 2011 indeed becomes small in nTAO (Fig. 10e), when the SSTs from Argo floats are included. The impact remains small in nBUOY8 (Fig. 10f) due to the inclusion of Argo observations, even if all buoy observations in the tropical Pacific are excluded. Certainly, the impact of TAO/ TRITON or all buoys on the El Niño event in November 2015 remains small (Figs. 10b and 10c) when SSTs from Argo floats are included. These results show an important role of Argo floats in realistically representing SSTs of ENSO events in both monthly ERSSTv5 and daily DOISST. When Argo observations are included in these two SST analyses, the impact of TAO/TRITON is very small during normal, El Niño, and La Niña years.

\section{Summary and discussion}

With the inclusion of ship observations, the relative roles of the recent observations from TAO/TRITON moored buoys, surface drifting buoys, and Argo floats in selected SST analyses are assessed by RMSDs using experiments of the monthly ERSSTv5 and daily DOISST 
(a) DOISSTwARG, Nov2015
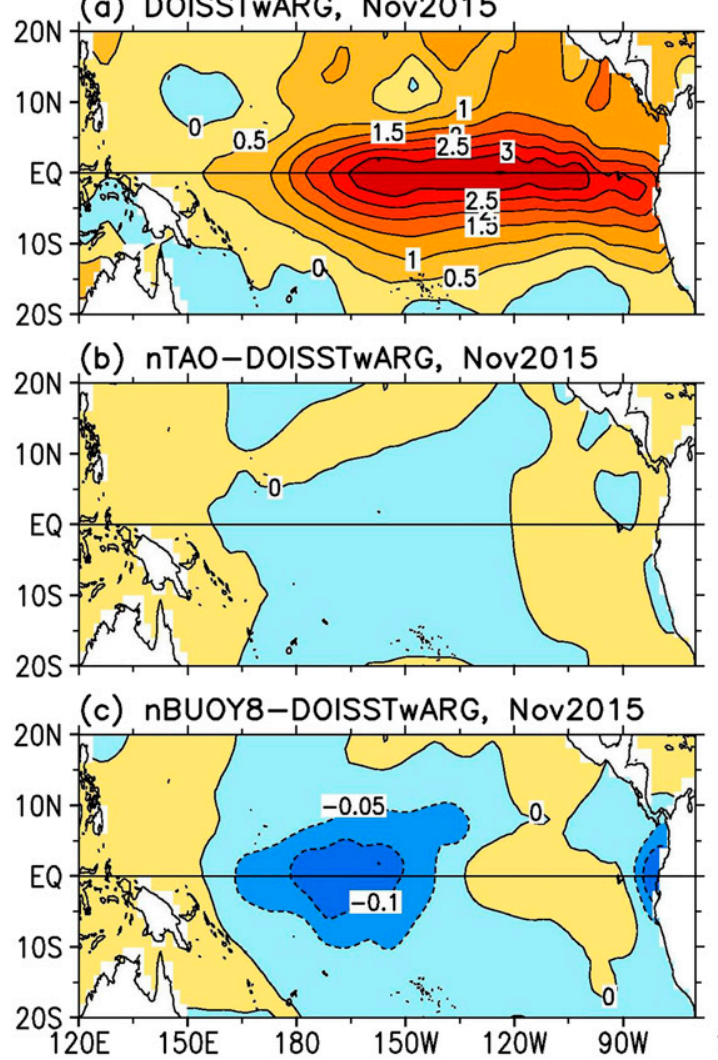

(d) DOISSTwARG, Jan2011
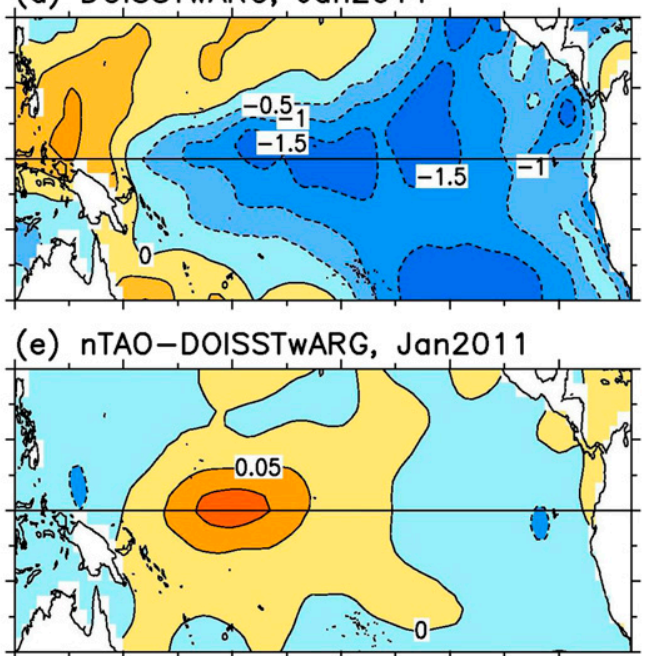

(f) nBUOY8-DOISSTwARG, Jan2011

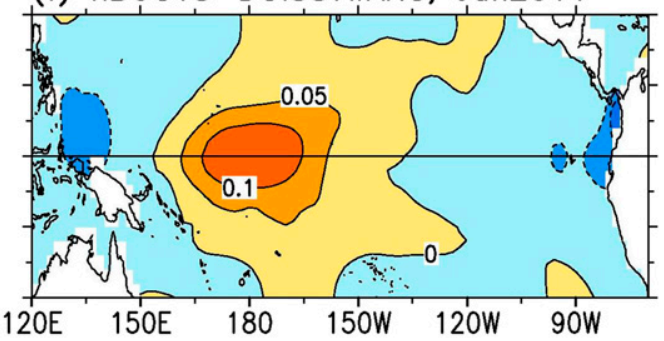

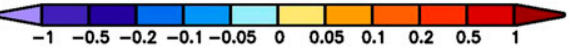

FIG. 10. (a) SSTA in DOISSTwARG and SSTA difference in (b) nTAO and (c) nBUOY8 relative to DOISSTwARG in November 2015. (d)-(f) As in (a)-(c), respectively, but for SSTA in January 2011. Contour intervals are $0.5^{\circ} \mathrm{C}$ in (a) and (d), and contours are $0^{\circ}, \pm 0.05^{\circ}, \pm 0.1^{\circ}, \pm 0.2^{\circ}$, and $\pm 0.5^{\circ} \mathrm{C}$ in (b), (c), (e), and (f). The DOISST data are box-averaged to monthly $2^{\circ} \times 2^{\circ}$ values for the purpose of comparing with ERSSTv5.

in the period of 2000-16. The major differences between ERSSTv5 and DOISST are that 1) the time resolution is 1 month in ERSSTv5 but 1 day in DOISST, 2) Argo observations are included in ERSSTv5 but not in DOISST, and 3) AVHRR-derived SSTs are not included in ERSSTv5 but included in DOISST. The experiments show that both types of buoys and Argo floats contribute to these SST analyses over the global oceans. Overall, the impact is larger from buoys than from Argo floats over the global oceans over 2000-16. However, the relative impact of buoys decreases from the 2000s to the 2010s, and the impact of Argo floats increases due to the increasing Argo observations. The trend of globally averaged SST over 2000-16 remains significant no matter whether buoy, Argo, or both observations are excluded, indicating that the SST warming trend reported earlier (Karl et al. 2015; Hausfather et al. 2017; Huang et al. 2017) may not be caused completely by the increasing observations of buoys and Argo floats.
In our analysis, the impact on the tropical Pacific SST from buoys (drifters and moorings), in comparison with Argo floats, is higher over 2000-05, is nearly equal over 2005-10, and becomes lower over 2010-16 due to the increasing number and area coverage from Argo floats. The magnitude of El Niño and La Niña decreases when the observations from buoys, Argo floats, or both are excluded, which indicates the importance of buoy and Argo observations in accurately representing ENSO events.

The role of TAO/TRITON observations in SST analyses depends on the availability of drifting buoy and Argo observations in the tropical Pacific. When observations from drifting buoys or Argo floats or both are included, TAO/TRITON observations are less important since the area coverage of TAO/TRITON is relatively low. Therefore, the impact of TAO/TRITON is very small during normal years and El Niño events. However, the impact of TAO/TRITON is evident 
during La Niña events, particularly when Argo observations are not included in the analysis systems. The evident impact of TAO/TRITON on La Niña events is attributed to a lower coverage of drifting buoys, which is further attributed to the stronger trade winds and therefore stronger equatorial near-surface divergent flows to disperse the surface drifters.

The impact of TAO/TRITON on La Niña events becomes more evident in daily DOISST. There are two reasons for the large impact of TAO/TRITON on La Niña events in DOISST. One is that the area coverage of drifting buoys is lower at the daily time scale in DOISST than at the monthly time scale in ERSSTv5. The other is that Argo observations are not included in daily DOISST whereas they are included in monthly ERSSTv5, and therefore the area coverage of observations becomes more sensitive to TAO/TRITON in daily DOISST than in monthly ERSSTv5. When Argo observations are included in daily DOISST, the impact of TAO/TRITON becomes very small, which is consistent with the conclusion based on the experiments of monthly ERSSTv5.

It should be stressed that TAO/TRITON moorings were designed to continuously monitor the ENSO activities in the tropical Pacific. The small impact of TAO/ TRITON on the monthly ERSSTv5 does not necessarily mean that TAO/TRITON's impact on higher-frequency SST analyses/products and other meteorological variables is small. For example, the impact of TAO/TRION on subsurface temperature and salinity is as large as Argo floats in some studies (Fujii et al. 2015; Xue et al. 2017). In the subsurface ocean, Argo floats only make profiling measurements when the floats rise to the surface to transmit data to satellites (nominally every 10 days). Therefore, the data coverage is relatively low and TAO/TRITON data become more important. It should be noted that the relative contributions of TAO/ TRITON and Argo floats to SST and subsurface temperature predictions in the tropical Pacific at different time scales may vary in different forecasting systems ( $\mathrm{Ji}$ and Leetmaa 1997; Fujii et al. 2015). It should also be noted that the analysis and results in this paper were based on the distributions of the past observations from ships, surface drifting buoys, moored buoys, and nearsurface Argo floats. This paper's analysis does not address the issues of optimal utilization of these ocean observing systems. Dedicated studies are needed to address that.

In conclusion, our experiments show that the observations from both buoys and Argo floats contributed to the studied SST analyses (ERSSTv5 and DOISST) over the global ocean over 2000-16. Overall and with the use of ship observations, the impact was higher from buoys than from Argo floats, but the impact from Argo floats clearly increased over 2000-16. The individual impact of buoys or Argo floats on globally averaged SST was small, while their joined impact was notable and may require a cautious treatment in examining the long-term SST trends. In the tropical Pacific, the impact of buoys was larger than that of Argo floats over 2000-05, but became less than that of Argo floats over 2010-16. The impact of TAO/TRITON was small during normal years and El Niño events and was large during La Niña events when Argo observations are not included. However, the impact of TAO/TRITON became small when Argo observations were included in the analysis systems.

Acknowledgments. The authors thank two anonymous reviewers who provided constructive suggestions in revising our manuscript. These suggestions have greatly improved our manuscript in readability and scientific soundness. The opinions expressed in this paper are those of the authors alone and do not necessarily reflect the official policy of NOAA, the Department of Commerce, or the U.S. government. G. R and L. Z are supported by the Natural Science Foundation of China (NSFC) (Grant 41575003).

NCEI monthly ERSSTv5 (https://doi.org/10.7289/ V5T72FNM) is accessible at ftp://ftp.ncdc.noaa.gov/ $\mathrm{pub} / \mathrm{data} / \mathrm{cmb} / \mathrm{ersst} / \mathrm{v} 5$, and its associated experiments can be accessed at ftp://ftp.ncdc.noaa.gov/pub/data/cmb/ ersst/v5/2017jc. NCEI daily OISST is accessible at ftp:// eclipse.ncdc.noaa.gov/pub/OI-daily-v2/IEEE, and its associated experiments can be accessed at $\mathrm{ftp} / / / \mathrm{ftp}$.ncdc.noaa. gov/pub/data/cmb/ersst/v5/2018jc. The SSTs from ships and buoys are retrieved from NCEI ICOADS R3.0 at https://doi.org/10.7289/V5CZ3562. Argo data are retrieved from the Global Data Assembly Centre (GDAC; https://doi.org/10.17882/42182) at http://www.seanoe.org/ data/00311/42182. Daily TAO/TRITON data are available at Pacific Marine Environmental Laboratory (http://www. pmel.noaa.gov/gtmba). CCI version 1.2 SST is available at the European Space Agency Climate Change Initiative (http://browse.ceda.ac.uk/browse/neodc/esacci/sst/data/lt/ Analysis/L4/v01.1).

\section{APPENDIX}

\section{ERSSTv5 Reconstruction}

ERSSTv5 SSTAs are reconstructed using EOTs (Smith et al. 2008). The EOTs are similar to empirical orthogonal functions except for being localized to a spatial scale of 5000 and $3000 \mathrm{~km}$ in longitude and latitude, respectively. The EOTs were trained by monthly, derived from weekly, OISST from 1982 to 2011: 


$$
R(x)=\sum_{i=1}^{140} f_{i} E_{i}(x)
$$

where $R(x)$ is reconstructed SSTA, $E_{i}(x)$ is the $i$ th EOT, and $f_{i}$ is the fitted reconstruction coefficient derived by minimizing the error variance over the global ocean domain $x$ :

$$
\begin{aligned}
& \text { Error }^{2}=\sum_{x}[O(x)-R(x)]^{2} \delta_{x} w(N, \varepsilon) \cos \phi_{x}, \\
& w(N, \varepsilon)=\frac{N_{s}+6.8 N_{b}}{N_{s}+6.8 N_{b}+\varepsilon^{2}},
\end{aligned}
$$

where $O(x)$ is SSTA superobservations that are averaged from available observations within a $2^{\circ} \times 2^{\circ}$ grid box. Also, $\delta_{x}$ is 1 when an SSTA superobservation is valid, and 0 otherwise; $\cos \phi_{x}$ is an area weighting function of latitude $\phi ; N_{s}$ and $N_{b}$ are the numbers of observations from ships and buoys within a grid box, respectively, and $N=N_{s}+6.8 N_{b}$. The factor of 6.8 is determined by the ratio of error variances of ship and buoy observations (Reynolds and Smith 1994). The term $\varepsilon$ is an averaged error of ship $\left(1.3^{\circ} \mathrm{C}\right)$ and buoy $\left(0.5^{\circ} \mathrm{C}\right)$ SST observations weighted by their observation numbers (Reynolds et al. 2002). The EOT fitting coefficient $f_{i}$ was calculated by solving linear equations using the lowerupper (LU) decomposition method (Press et al. 1992).

During the SSTA reconstruction, not all 140 EOTs were actually used in the reconstruction of any given monthly field. An EOT mode was accepted only if its variance ratio $r_{i}$ is greater than an acceptance criterion value of 0.1 . The variance ratio $r_{i}$ was defined as a ratio of the effective variance and the total variance of that EOT mode:

$$
r_{i}=\left[\sum_{x} E_{i}^{2}(x) \delta_{x} \cos \phi_{x}\right] /\left[\sum_{x} E_{i}^{2}(x) \cos \phi_{x}\right] .
$$

The effective variance is calculated within the area of an EOT mode where superobservations are valid, while the total variance is calculated without considering superobservations. The acceptance criterion avoids undersampled EOTs being used in the reconstruction.

\section{REFERENCES}

Argo, 2018: Argo float data and metadata from Global Data Assembly Centre (Argo GDAC). SEANOE, accessed 3 February 2017, http://doi.org/10.17882/42182.

Balmaseda, M., D. Anderson, and A. Vidard, 2007: Impact of Argo on analyses of global ocean. Geophys. Res. Lett., 34, L16605, https://doi.org/10.1029/2007GL030452.

Barale, V., J. F. R. Gower, and L. Alberotanza, Eds., 2010: Oceanography from Space: Revisited. Springer, 374 pp.
Boening, C., J. K. Willis, F. W. Landerer, R. S. Nerem, and J. Fasullo, 2012: The 2011 La Niña: So strong, the oceans fell. Geophys. Res. Lett., 39, L19602, https://doi.org/10.1029/ 2012 GL053055.

Freeman, E., and Coauthors, 2017: ICOADS Release 3.0: A major update to the historical marine climate record. Int. J. Climatol., 37, 2211-2232, https://doi.org/10.1002/joc. 4775.

Fujii, Y., and Coauthors, 2015: Evaluation of the tropical Pacific observing system from the ocean data assimilation perspective. Quart. J. Roy. Meteor. Soc., 141, 2481-2496, https://doi.org/ 10.1002/qj.2579.

Gasparin, F., D. Roemmich, J. Gilson, and B. Cornuelle, 2015: Assessment of the upper-ocean observing system in the equatorial Pacific: The role of Argo in resolving intraseasonal to interannual variability. J. Atmos. Oceanic Technol., 32, 16681688, https://doi.org/10.1175/JTECH-D-14-00218.1.

Hausfather, Z., K. Cowtan, D. C. Clarke, P. Jacobs, M. Richardson, and R. Rohde, 2017: Assessing recent warming using instrumentally homogeneous sea surface temperature records. Sci. Adv., 3, e1601207, https://doi.org/10.1126/sciadv.1601207.

Hirahara, S., M. Ishii, and Y. Fukuda, 2014: Centennial-scale sea surface temperature analysis and its uncertainty. J. Climate, 27, 57-75, https://doi.org/10.1175/JCLI-D-12-00837.1.

Huang, B., Y. Xue, and D. W. Behringer, 2008: Impacts of Argo salinity in NCEP Global Ocean Data Assimilation System: The tropical Indian Ocean. J. Geophys. Res., 113, C08002, https://doi.org/10.1029/2007JC004388.

,$- \ldots$, H. Wang, W. Wang, and A. Kumar, 2012: Mixed layer heat budget of the El Niño in NCEP Climate Forecast System. Climate Dyn., 39, 365-381, https://doi.org/10.1007/s00382-0111111-4.

_, M. L'Heureux, J. Lawrimore, C. Liu, H.-M. Zhang, V. Banzon, Z.-Z. Hu, and A. Kumar, 2013: Why did large differences arise in the sea-surface temperature datasets across the tropical $\mathrm{Pa}$ cific during 2012? J. Atmos. Oceanic Technol., 30, 2944-2953, https://doi.org/10.1175/JTECH-D-13-00034.1.

_ temperature version 4 (ERSST.v4), Part I. Upgrades and intercomparisons. J. Climate, 28, 911-930, https://doi.org/ 10.1175/JCLI-D-14-00006.1.

- W. Wang, C. Liu, V. F. Banzon, H.-M. Zhang, and J. Lawrimore, 2015b: Bias adjustment of AVHRR SST and its impacts on two SST analyses. J. Atmos. Oceanic Technol., 32, 372-387, https://doi.org/10.1175/JTECH-D-14-00121.1.

— M. L'Heureux, Z.-Z. Hu, and H.-M. Zhang, 2016: Ranking the strongest ENSO events while incorporating SST uncertainty. Geophys. Res. Lett., 43, 9165-9172, https://doi.org/ 10.1002/2016GL070888.

— , and Coauthors, 2017: Extended reconstructed sea surface temperature version 5 (ERSSTv5): Upgrades, validations, and intercomparisons. J. Climate, 30, 8179-8205, https://doi.org/ 10.1175/JCLI-D-16-0836.1.

- W. Angel, T. Boyer, L. Cheng, G. Chepurin, C. Liu, and H.-M. Zhang, 2018: Evaluating SST analyses with independent ocean profile observations. J. Climate, 31, 5015-5030, https:// doi.org/10.1175/JCLI-D-17-0824.1.

Ishii, M., A. Shouji, S. Sugimoto, and T. Matsumoto, 2005: Objective analyses of sea-surface temperature and marine meteorological variables for the 20th century using ICOADS and the Kobe Collection. Int. J. Climatol., 25, 865-879, https://doi.org/ 10.1002/joc. 1169 .

Ji, M., and A. Leetmaa, 1997: Impact of data assimilation on ocean initialization and El Niño prediction. Mon. Wea. Rev., 125, 
742-753, https://doi.org/10.1175/1520-0493(1997)125<0742: IODAOO $>2.0 . \mathrm{CO} ; 2$.

Karl, T. R., and Coauthors, 2015: Possible artifacts of data biases in the recent global surface warming hiatus. Science, 348, 14691472, https://doi.org/10.1126/science.aaa5632.

Kennedy, J. J., N. A. Rayner, R. O. Smith, D. E. Parker, and M. Saunby, 2011a: Reassessing biases and other uncertainties in sea surface temperature observations measured in situ since 1850: 1. Measurement and sampling errors. J. Geophys. Res., 116, D14103, https://doi.org/10.1029/2010JD015218.

$\leftarrow,-,-, \ldots$, and $\_, 2011 \mathrm{~b}$ : Reassessing biases and other uncertainties in sea surface temperature observations measured in situ since 1850: 2: Biases and homogenization. J. Geophys. Res., 116, D14104, https://doi.org/10.1029/2010JD015220.

L'Heureux, M. L., and Coauthors, 2017: Observing and predicting the 2015/16 El Niño. Bull. Amer. Meteor. Soc., 98, 1363-1382, https://doi.org/10.1175/BAMS-D-16-0009.1.

Lumpkin, R., and M. Pazos, 2007: Measuring surface currents with Surface Velocity Program drifters: The instrument, its data, and some recent results. Lagrangian Analysis and Prediction of Coastal and Ocean Dynamics, A. Griffa et al., Eds., Cambridge University Press, 39-67, https://doi.org/10.1017/ CBO9780511535901.003.

Matthews, J. B. R., 2013: Comparing historical and modern methods of sea surface temperature measurement. Part 1: Review of methods, field comparisons and dataset adjustments. Ocean Sci., 9, 683-694, https://doi.org/10.5194/os-9-683-2013.

McPhaden, M. J., and Coauthors, 1998: The Tropical Ocean-Global Atmosphere Observing System: A decade of progress. J. Geophys. Res., 103, 14 169-14240, https://doi.org/10.1029/97JC02906.

Merchant, C. J., and Coauthors, 2012: A 20 year independent record of sea surface temperature for climate from along-track scanning radiometers. J. Geophys. Res., 117, C12013, https:// doi.org/10.1029/2012JC008400.

— climate applications from Phase 1 of the European Space Agency Climate Change Initiative (SST CCI). Geosci. Data J., 1, 179-191, https://doi.org/10.1002/gdj3.20.

Oke, P. R., and A. Schiller, 2007: Impact of Argo, SST, and altimeter data on an eddy-resolving ocean reanalysis. Geophys. Res. Lett., 34, L19601, https://doi.org/10.1029/2007GL031549.

Philander, S. G. H., 1990: El Niño, La Niña, and the Southern Oscillation. Academic Press, $289 \mathrm{pp}$.

Press, W. H., B. P. Flannery, S. A. Teukolsky, and W. T. Vetterling, 1992: LU decomposition and its applications. Numerical Recipes in FORTRAN: The Art of Scientific Computing, 2nd ed., Cambridge University Press, 34-42.
Rayner, N. A., D. E. Parker, E. B. Horton, C. K. Folland, L. V. Alexander, D. P. Rowell, Kent E., and A. Kaplan, 2003: Global analyses of sea surface temperature, sea ice, and night marine air temperature since the late nineteenth century. J. Geophys. Res., 108, 4407, https://doi.org/10.1029/2002JD002670.

Reynolds, R. W., and T. M. Smith, 1994: Improved global sea surface temperature analyses using optimum interpolation. J. Climate, 7, 929-948, https://doi.org/10.1175/1520-0442(1994)007<0929: IGSSTA $>2.0 . \mathrm{CO} ; 2$.

— N. N. Aayner, T. M. Smith, D. C. Stokes, and W. Wang, 2002: An improved in situ and satellite SST analysis for climate. J. Climate, 15, 1609-1625, https://doi.org/10.1175/15200442(2002)015<1609:AIISAS > 2.0.CO;2.

—, T. M. Smith, C. Liu, D. B. Chelton, K. S. Casey, and M. G. Schlax, 2007: Daily high-resolution blended analyses for sea surface temperature. J. Climate, 20, 5473-5496, https://doi.org/ 10.1175/2007JCLI1824.1.

Roemmich, D., and Coauthors, 2001: The global array of profiling floats. Observing the Ocean in the 21st Century, C. J. Koblinsky and N. R. Smith, Eds., Australian Bureau of Meteorology, 248-258.

Smith, T., R. W. Reynolds, T. C. Peterson, and J. Lawrimore, 2008: Improvements to NOAA's historical merged land-ocean surface temperature analysis (1880-2006). J. Climate, 21, 2283-2296, https://doi.org/10.1175/2007JCLI2100.1.

Teng, C-C., S. Cucullu, S. McArthur, C. Kohler, B. Burnett, and L. Bernard, 2009: Buoy vandalism experienced by NOAA National Data Buoy Center. OCEANS 2009, Biloxi, MS, MTS/IEEE, https://doi.org/10.23919/OCEANS.2009.5422389.

Tollefson, J., 2014: El Niño tests forecasters. Nature, 508, 20-21, https://doi.org/10.1038/508020a.

van den Dool, H. M., S. Saha, and A. Johansson, 2000: Empirical orthogonal teleconnections. J. Climate, 13, 1421-1435, https:// doi.org/10.1175/1520-0442(2000)013<1421:EOT>2.0.CO;2.

von Storch, H., and F. W. Zwiers, 1999: Statistical Analysis in Climate Research. Cambridge University Press, 484 pp.

Woodruff, S. D., and Coauthors, 2011: ICOADS release 2.5: Extensions and enhancements to the surface marine meteorological archive. Int. J. Climatol., 31, 951-967, https://doi.org/ 10.1002/joc. 2103 .

Xue, Y., and Coauthors, 2017: Evaluation of tropical Pacific observing systems using NCEP and GFDL ocean data assimilation systems. Climate Dyn., 49, 843-868, https://doi.org/ 10.1007/s00382-015-2743-6.

Zhang, R.-H., F. Zheng, J. Zhu, and Z. Wang, 2013: A successful real-time forecast of the 2010-11 La Niña event. Sci. Rep., 3, 1108, https://doi.org/10.1038/srep01108. 